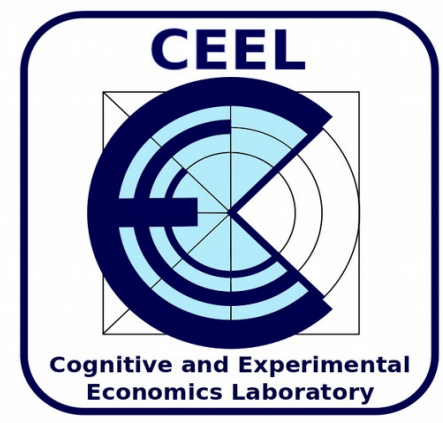

Tatiana Balmus, Juergen Huber and Matteo Ploner More competition in delegated portfolio management: A win-win situation? An
experimental analysis.

CEEL Working Paper 1-19

Cognitive and Experimental Economics Laboratory

Via Inama, 538100 Trento, Italy

http://www-ceel.economia.unitn.it

tel. +39.461 .282313$ 


\title{
More competition in delegated portfolio management: A win-win situation? An experimental analysis.
}

\author{
Tatiana Balmus* Juergen Huber ${ }^{\dagger} \quad$ Matteo Ploner ${ }^{\ddagger}$
}

January 3, 2019

\begin{abstract}
With a novel design, we investigate how competition between fund managers and disclosure of other managers' fees and performance influence fees, risk taken, earnings and investor concentration in a fund management experiment. We find that more competition and disclosure leads to a significant reduction of fees - the relative decrease being larger for Management Fees than for Performance Fees. While the decrease in fees does not affect manager's investment strategies, it significantly increases investors' readiness to entrust their funds to a manager. This leads to higher overall earnings, with the benefits going to investors and those fund managers who are able to attract investors. While there is an extensive literature arguing that a competitive environment may lead to unwanted outcomes, our results suggest that more competition is mostly beneficial to investors and those fund managers that succeed in attracting investors.
\end{abstract}

JEL codes: D14, D18, G11, G41

Keywords: behavioral finance, Performance Fee, Management Fee, competition, disclosure

\footnotetext{
*School of Social Sciences, University of Trento, Italy

${ }^{\dagger}$ Department of Banking and Finance, University of Innsbruck, Austria

${ }^{\ddagger}$ Corresponding author. CEEL-DEM, University of Trento, Italy. Email: matteo.ploner@unitn.it.
} 


\section{Introduction}

"Where are the yachts of the investors?" asks Simon Lack in his famous book "The Hedge Fund Mirage" (Lack, 2012), pointedly highlighting the high fees hedge fund managers often demand from investors. With the famous " $2 / 20$ rule" (managers earn 2 percent of assets under management plus 20 percent of profits) the most successful of them earn billions per year. Average mutual fund managers are less glamorous and less well-paid, but they still demand on average 1.5 percent of assets under management as fees - in stark contrast to less than 10 basis points the largest ETFs cost today (Malkiel, 2013).

Delegated portfolio management is one of the cornerstones of financial intermediation as it provides an effective channel connecting lenders and borrowers (Gorton and Winton, 2003). In 2017, 56.2 million U.S. households owned mutual funds and the total net assets of mutual funds amounted to 18,746 billion dollars after a growth of $56.2 \%$ in the interval $2007-2017 .^{1}$ Investors transfer their resources to fund managers, who invest these resources into securities delivering a return for investors. The net returns for investors, i.e., the difference between returns from the investment activity and the fees paid to managers, either as a proportion of the traded wealth (Management Fee) and/or as a proportion of positive returns (Performance Fee).

The incentive structure of delegated portfolio management embeds a potential conflict of interests between managers and investors. In particular, the limited liability of managers induced by left-truncated Performance Fees may result in excessive risk-taking by managers (for an early contribution, see Grinblatt and Titman, 1989), and this may even be exacerbated by an increase in competition among managers (Rajan, 2006; Thanassoulis, 2012).

Our contribution focuses on the impact of competition among managers on fees, risk taken, the amounts of money managed, and the distribution of returns among investors and managers. Specifically, we assess how higher competitive pressure, proxied by (i) whether investors can choose among competing managers, and (ii) how much information managers have about

\footnotetext{
${ }^{1}$ These figures are obtained from the 2018 Investment Company Fact Book published by the Investment Company Institute (ICI).
} 
competing managers' fees and returns, affects the evolution of Management Fees and Performance Fees. These two aspects of competition have important implications for real-world markets. As an example, with reference to the possibility for the investors to choose the manager, hedge funds are available only to individuals who meet certain capital requirements, while publicly traded funds are usually accessible to all investors. With reference to information about others' practices, mutual funds face higher transparency requirements relative to hedge funds.

We measure how competition affects the amount of funds handled by individual managers and the returns of investors and managers. Empirical works deliver mixed evidence on these issues; some authors arguing that fiercer competition among managers leads to a decrease in fees, as predicted by economic theory, and others arguing in the opposite direction (see references below).

We find in our experimental setting that higher competitive pressure reduces fees paid by investors, with a stronger impact for Management Fees than for Performance Fees. This seems to encourage market participation and significantly increases the share of investors entrusting their endowment to fund managers. Looking at overall earnings, fiercer competition improves the returns of investors and of "successful" managers who are able to attract investors.

\section{Positioning of the study and research ques- tions}

Portfolio management is usually delegated to professionals, which implies the existence of an agency relationship between the investor (principal) and the portfolio manager (agent). As in most agency problems, moral hazard is likely to emerge because the interests of the investors and those of the agents are not perfectly aligned (see Grinblatt and Titman, 1989). Specifically, the individual who decides on the allocation of funds is not the one who bears the associated risk (among others see, Allen, 2001; Kritzman, 1987). From 
a regulatory perspective, this consideration highlights a potential source of failure of regulatory oversight when the conflict of interests of investors and portfolio managers is not taken into account (Bebchuk and Spamann, 2009).

The issue of optimal contract design in delegated portfolio management has been widely investigated from a theoretical point of view (for a review see Stracca, 2006). As an empirical observation, we see that hedge fund managers usually apply a $2 / 20$ fee structure, taking $2 \%$ of the managed funds (Management Fee) and 20\% of the realized returns (Performance Fee). Evidence suggests that this pricing structure is perceived as unjustified by many investors (Linciano et al., 2016) and may also lead to distortive behavior in terms of risk exposure, as the Management Fee often out-weights the importance of the Performance Fee. ${ }^{2}$

Our work focuses on the impact of competition on fees and investment decisions. Standard economic theory predicts that greater competition leads to lower fees, compared to monopolies. However, previous empirical research provides a mixed picture of the impact of competition on fees. Despite increased market competition, charged fees have risen substantially in some markets, while they have fallen overall (Coates and Hubbard, 2007; Malkiel, 2013). In a recent contribution, Parida and Tang (2017) show funds operating in more competitive markets to increase the charged fees, with the expense ratio driven mostly by the increase in Management Fees (which, however, are not caused by higher costs of fund operations). In line with the view of Christoffersen and Musto (2002), Parida and Tang (2017) explain this behavior as being consistent with strategic fee setting (by fund managers) who increase the Management Fees to take advantage of the inelastic demand curve, which, consequently, reduces the net return of investors.

The amount in fees paid by investors may also have implications for the behavior of managers. In line with the "charter value hypothesis" (Allen and Gale, 2004), managers obtaining lower fees may engage in riskier investments to enjoy the benefits of higher expected returns and exploit the implicit limited liability offered by Performance Fees (Grinblatt and Titman, 1989).

\footnotetext{
${ }^{2}$ As an example, see the Financial Times' article "Hedge fund investors question '2 and 20' fees" by Lindsay Fortado (June 6, 2017).
} 
Following this line of reasoning, higher competition may reduce fees but foster excessive risk-taking by managers. As illustrated by Rajan (2006), this may results in systemic instability of the financial system.

Here, we pay attention not only to the level of fees but also to the interplay between Management and Performance Fees. Several authors investigated the implications of the dual nature of fees in financial markets. Elton et al. (2003) report better stock selection and more risk taking among funds with Performance Fees compared to funds without Performance Fees. Furthermore, they report that after a bad performance managers increase risk-taking while they decrease it after a good performance. Gil-Bazo and Ruiz-Verdú (2009) argue that there is evidence of a negative relation between charged fees and the performance of the funds before fees. The authors argue that their empirical analysis supports a strategic-pricing explanation, according to which funds which have a lower performance and face a less elastic demand charge higher fees. A different perspective is presented by Broeders et al. (2017), who investigate the relationship between investment returns and paid Performance Fees and do not find significant evidence that pension funds paying Performance Fees to asset managers for active investing perform better or worse than pension funds that do not pay Performance Fees. Thus, evidence exploring the relationship between fees and performance is mixed, and an experimental exploration in the lab seems appropriate to shed light on some of the open questions.

Our experimental design aims at clearly identifying the impact of competitive forces on fees and market participation. Specifically, we investigate two main dimensions of competition by experimentally manipulating (i) whether investors can choose among several competing fund managers or only face a yes/no decision on one specific manager; and (ii) the degree of information about the fees and performance managers receive about other managers. With this experimental setting, we try to answer the following research questions that emerge from the existing literature:

- RQ1: How do competition and disclosure affect fees?

- which competitive element, if either, is more effective in reducing 
fees?

- do competition and disclosure affect Management Fees or Performance Fees more strongly?

- RQ2: How do competition and disclosure affect investment strategies?

- do managers invest differently under more competition?

- RQ3: How do competition and disclosure affect market participation?

- which competitive element is more effective in promoting market participation, i.e., induces investors to entrust their funds to a manager rather than invest risk-free?

- RQ4: How do competition and disclosure affect market concentration?

- which element/s affect the concentration of investments among managers?

- RQ5: How do competition and disclosure influence the earnings of managers and investors?

\section{Experimental Setup}

\subsection{Choice Task}

In our experiment, participants interact in groups of 12 , with four participants assigned to the role of Managers and eight participants to the role of Investors. Managers are uniquely identified by labels $\mathrm{A}, \mathrm{B}, \mathrm{C}$, and $\mathrm{D}$, and roles and group compositions are kept constant throughout the experimental session.

Participants face a sequential choice task which is repeated for an uncertain number of periods (between 10 and 25). The basic structure of the task is the following: i) managers post a combination of Management Fee and Performance Fee they demand to manage investors' funds; ii) managers decide how to allocate funds among three possible alternatives that differ in 
terms of risk/return combination; iii) investors decide whether and to whom to allocate their money, knowing the fees asked by each manager but not their investment strategies; iv) returns from the investments are computed and the fees paid accordingly.

If an investor entrusts her endowment to a manager to invest, the manager is entitled to the payment of a Management Fee (M) and (conditional upon a positive profit) a Performance Fee $(\mathrm{P})$. Within certain limits, managers are free to choose the fee combination they ask for the portfolio management. The 16 possible combinations of $\mathrm{M}$ and $\mathrm{P}$ among which managers can choose in our experiment are shown in Table 1.

Table 1. Possible combinations of Management Fee (M) and Performance Fee $(\mathrm{P})$ in the experiment.

\begin{tabular}{|c|c|c|c|c|c|}
\hline & \multicolumn{5}{|c|}{$\begin{array}{c}\text { Performance Fee (P) } \\
\text { (\% of profits) }\end{array}$} \\
\hline \multirow{3}{*}{$\begin{array}{c}\text { Management Fee (M) } \\
\text { (\% of endowment) }\end{array}$} & & $\mathbf{0 \%}$ & $\mathbf{1 0 \%}$ & $\mathbf{2 0 \%}$ & $\mathbf{3 0 \%}$ \\
\cline { 2 - 6 } & $\mathbf{0 \%}$ & $0 / 0$ & $0 / 10$ & $0 / 20$ & $0 / 30$ \\
\cline { 2 - 6 } & $\mathbf{1 \%}$ & $1 / 0$ & $1 / 10$ & $1 / 20$ & $1 / 30$ \\
\cline { 2 - 6 } & $\mathbf{2 \%}$ & $2 / 0$ & $2 / 10$ & $2 / 20$ & $2 / 30$ \\
\cline { 2 - 6 } & $\mathbf{3 \%}$ & $3 / 0$ & $3 / 10$ & $3 / 20$ & $3 / 30$ \\
\hline
\end{tabular}

The Management Fee-a percentage of the endowment-is paid independently of the realized profit, while the Performance Fee-a percentage of the realized profit-is paid only if a positive profit is realized. Thus, the necessary requirement for the payment of the Management Fee is an investor's decision to entrust his endowment to a manager, while for the Performance Fee the further requirement is the realization of a positive profit, defined as the difference between the final value and the initial value of the investment.

After having observed the combination of fees posted by all four managers, each investor can decide whether and (in half of the treatments) to whom to allocate their money, i.e., whether or not to participate in the investment market. When an investor chooses to allocate his money to a manager, the complete endowment is allocated to the chosen manager; the endowment 
cannot be partially allocated or allocated to more than one manager. When the investor decides not to entrust her endowment to any of the managers, the endowment is invested risk-free at $1 \%$.

Before knowing how many investors they will have, managers choose the share of the disposable wealth to be allocated to an Index, a Stock and a (risk-free) Bond. The three assets differ in expected returns $(\mu)$ and standard deviation $(\sigma)$. The returns of the individual stock and those of the index are independent random draws, and thus, uncorrelated. The characteristics of the investment strategies are as follows:

Table 2. Characteristics of the financial assets in which fund managers can invest.

\begin{tabular}{|c|c|c|}
\hline & Average return $\mu$ & Standard deviation $\sigma$ \\
\hline Stock & $6 \%$ & $20 \%$ \\
\hline Index & $5 \%$ & $10 \%$ \\
\hline Bond & $1 \%$ & $0 \%$ \\
\hline
\end{tabular}

The manager can freely invest any fraction of money entrusted to her in the three financial instruments, with the only conditions being that the sum of the percentages must equal $100 \%$, and fractions cannot be negative. Managers are not allowed to borrow money and have no own endowment.

Given this setting, manager $i$ 's earning in a period is $\pi_{i}=n_{i} \bar{E}\left(M_{i}+P_{i} \rho\right)$, where $n_{i}$ is the number of investors who entrust their endowment to manager $i, M_{i}$ is the level of the Management Fee posted by $i, \bar{E}$ is the the investor's individual endowment, $P_{i}$ is Performance Fee posted by $i$ and $\rho$ is the profit (in percent) realized by $i$. Accordingly, investor $j$ 's earnings when entrusting resources to manager $i$ are $\pi_{j}=\bar{E}\left(\rho\left(1-P_{i}\right)-M_{i}\right)$.

\section{$3.2 \quad$ Treatments}

We implement a $2 \times 2$ design in a between-subject setting: the two-level (Yes/No) factors which are experimentally manipulated are Competition between managers and Disclosure of fees and returns of other managers (see Table 3). 
Table 3. Overview of the four Treatments of the experiment with treatment variables Competition and Disclosure.

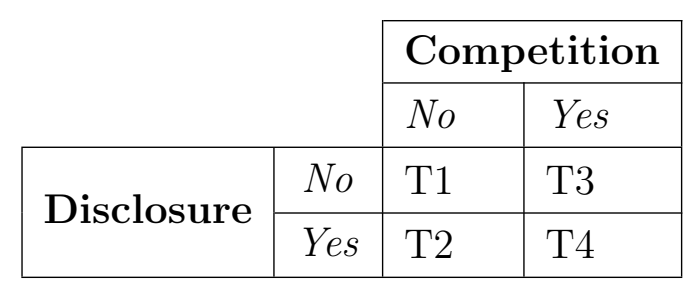

In condition No Competition, each manager is permanently and uniquely matched with two investors. Thus, an investor can only choose whether to entrust her money to her assigned manager or not participate in the investment market and invest at the risk-free rate. By contrast, in condition Competition, a manager can potentially attract all eight investors in his group. Investors, after having observed the fees posted by the four managers in their group, can freely choose a manager among the four, or decide to not participate in the market and invest at the risk-free rate.

In condition No Disclosure, managers see only their own performance and fees in the previous period before posting their fees, but they have no access to the same information about other managers. In condition Disclosure, in addition to the information about their own past performance and fees, managers see past performance and fees posted by other managers before posting their own fees. ${ }^{3}$ Investors always see the fees and performances of the four managers in their group.

\subsection{Procedures and Participants}

Participants were told that the number of periods would be between 10 and 25. We had a random ending in the first session after period 13 and implemented the same number of periods in all subsequent sessions. Before the 13 main trading periods began, managers were given the opportunity to become

\footnotetext{
${ }^{3}$ An example of the (different) screens shown on managers' displays is presented in Figures 6 and 7 in the Appendix.
} 
acquainted with the investment setting in six training periods. The outcome of these periods had no influence on their final payment.

The rationale for the training periods is twofold. On the one hand, managers need some training periods to become familiar with the setting. On the other hand, before starting real periods investors need to have some information on managers' performance. Accordingly, in the first four (out of six) training periods, the performance of the managers (return of the investments strategy) remains private information. The returns of the last two training periods, however, are also shown to investors. ${ }^{4}$ Investors see the track-record of managers' performance, but not their investment strategy, which always remains private information. Investors see a table indicating the label of the manager (A, B, C, D) and the corresponding investment return in the previous period (for a screenshot of the computer interface, see Figures 6 and 8 in the Appendix).

The experiment is fully computerized and programmed with zTree (Fischbacher, 2007). During the experiment, all money amounts were expressed in Taler, and, at the beginning of each period, each investor received an endowment of 10,000 Taler (while managers did not get any endowment). The exchange rate applied from Taler to Euro is 200 Taler $=1$ Euro.

For each of the four experimental conditions, we ran six sessions for a total of 24 sessions with 12 participants each for a total of 288 students. To capture the real-world difference in knowledge (and skills) between managers and investors and to ensure that managers are familiar with concepts like "expected return", "standard deviation" and "correlation" we restrict participation as portfolio managers to only Master's students in finance, who are familiar with issues like portfolio management, returns and volatility. No restrictions are set for participants acting as investors.

Half of the experimental sessions were conducted at the University of Innsbruck (Austria) and the other half at the University of Trento (Italy). ${ }^{5}$

\footnotetext{
${ }^{4}$ This information is provided also to the other managers in condition Disclosure.

${ }^{5}$ We had 144 participants in each location. Participants of the two universities are similar in terms of gender composition, age, and number of risk-averse individuals. Furthermore, as Falk et al. (2015) point out, the two countries display similar risk-taking attitudes.
} 
We ran the experiments in Innsbruck and Trento to have enough Master students in finance to act as fund managers. We also see this as a robustness check - one that is passed, as we find no significant differences between the results in the two labs.

Each subject participated in only one session. In total, each experimental session lasted approximately $70 \mathrm{~min}$., including $20 \mathrm{~min}$. to read aloud the written instructions, the main experiment (including the six trial periods), a risk-elicitation task, a financial literacy questionnaire, and general demographic questions. Participants realizing a loss could not leave the room before completing a further stage, which was a simple counting task. ${ }^{6}$ The average payout to subjects was 9.3 Euros.

Immediately after the investment task and before payments are shown, risk preferences are elicited-participants have to choose one prospect in a noloss context followed by a setting in which prospects present a probability to incur a loss (Eckel and Grossman, 2008). One of the two selected prospects is then played for real, and the outcome is added to (or subtracted from) the final payment. The experiment concludes with a questionnaire on financial literacy (Van Rooij et al., 2011) and demographics and then the payment. ${ }^{7}$

\section{Results}

We present results in the following sequence: in section 4.1, we focus on managers' choices, with particular attention to posted fees and investment strategies. In section 4.2 , the choices of investors are analyzed, with a focus on market participation and concentration of investments. Finally, the earnings of participants in alternative experimental conditions are discussed in section 4.3.

\footnotetext{
${ }^{6}$ Whenever a loss is realized, the outcome for the manager is zero paid Performance Fee. Hence, the loss is incurred only by investors, who suffer not only the realized loss in the selected periods, but also the Management Fees they have to pay in that period. Investors who had net losses in the selected periods had to count numbers in tables. The average tables counted to recover losses was 1.1, with most investors not having to count any tables.

${ }^{7}$ The English version of the questionnaires is shown in the Appendix.
} 


\subsection{Managers' Fees and Decisions}

\section{Fees}

We first analyze Management Fees (percent of assets under management, irrespective of profits or losses) and then Performance Fees (percent of the profits achieved).

Figure 1 provides a representation of posted and paid Management Fees. The diamond dots show the average posted fee in each period, while the round dots depict the average paid fee. The two fees can differ, as investors may flock to "low-fee-managers" in condition Competition or choose the riskfree rate if they consider fees too high in all conditions. Table 4 complements the information gathered from the figure with descriptive statistics of fees in each of the experimental conditions. 
Figure 1. Development of Management Fees in each of the four conditions across the 13 main periods.

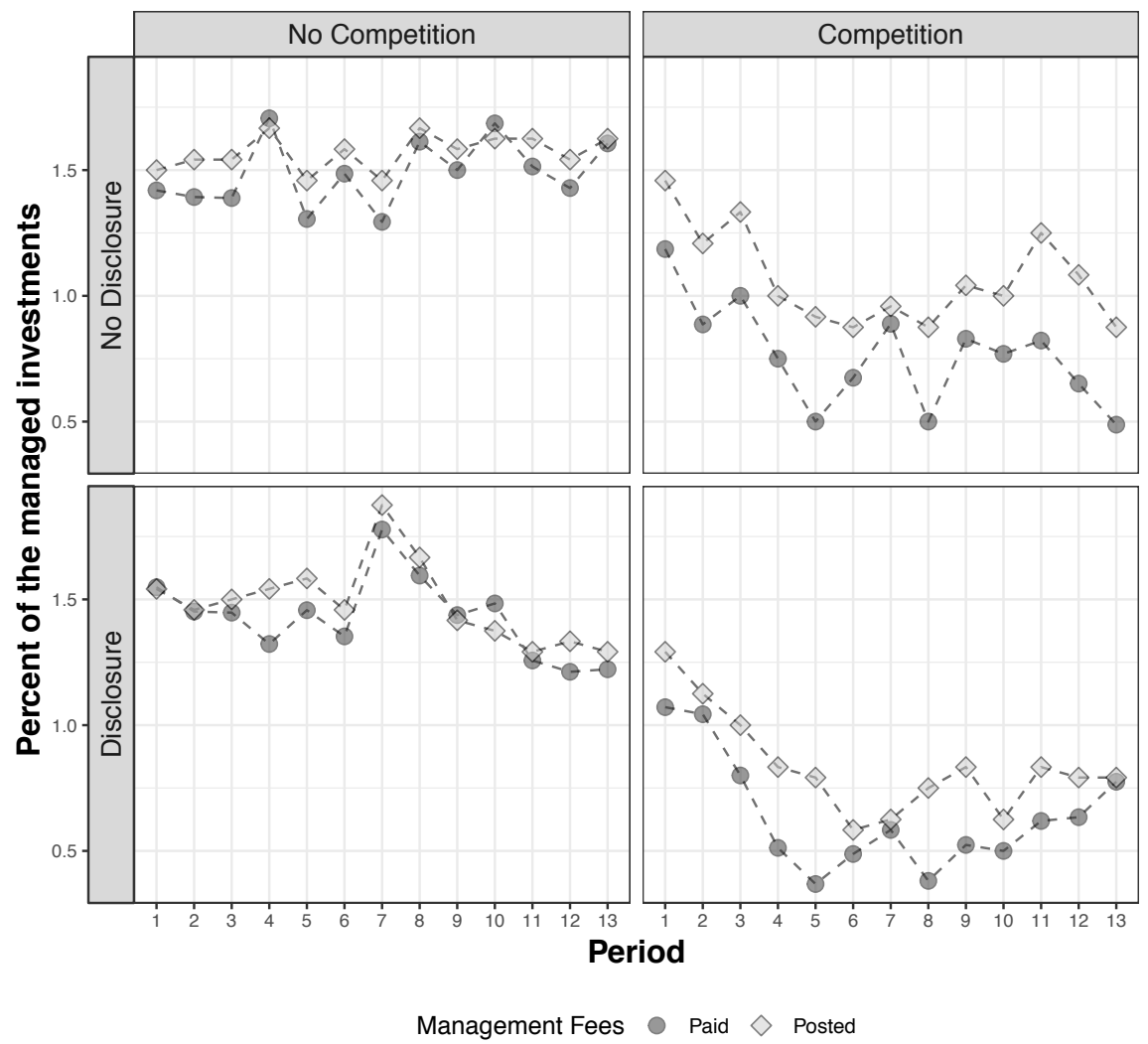

Note: For each experimental condition, diamonds show the average posted Management Fees in a period, while dark grey circles depict the average paid Management Fees in each period. 
Table 4. Average Management Fees by Condition (standard deviation in brackets).

\begin{tabular}{lll}
\hline Condition & Posted & Paid \\
\hline T1 (No Competition; No Disclosure) & $1.57(0.82)$ & $1.49(0.80)$ \\
T2 (Competition; No Disclosure) & $1.07(0.80)$ & $0.76(0.73)$ \\
T3 (No Competition; Disclosure) & $1.49(0.91)$ & $1.43(0.91)$ \\
T4 (Competition; Disclosure) & $0.84(0.88)$ & $0.64(0.74)$ \\
\hline
\end{tabular}

As Figure 1 shows, Management Fees are quite stable around 1.5 percent of assets under management in the two No Competition-treatments (T1 and T3), while fees are lower from the start and display a pronounced downward trend in Competition treatments T2 and T4. Posted Management Fees are, on average, about $1 / 3$ lower with competition between managers than without competition. The difference is even larger for paid fees, which are about 50 percent lower when managers have to compete for investors. Disclosure, by contrast, has a comparatively smaller effect on posted fees. The lowest average Management Fees (posted and paid) are observed in condition T4 (Competition/Disclosure), while the highest fees are present in condition T1 (No Competition/No Disclosure).

While average posted and paid fees are very similar in T1 and T3 (No Disclosure) at 1.43 to 1.57 percent, investors pay on average about $1 / 4$ less than the average posted fee with competition (in T2 and T4, paying only 0.76 and 0.64 percent, respectively), as managers posting lower fees are chosen more frequently than their competitors with higher fees (see regressions in Tables 6 and 7).

Turning to Performance Fees, Figure 2 depicts their development in each of the four conditions. Table 5 complements the information from the figure with descriptive statistics on fees in each experimental condition. 
Figure 2. Development of Performance Fees in each of the four conditions across the 13 main periods.

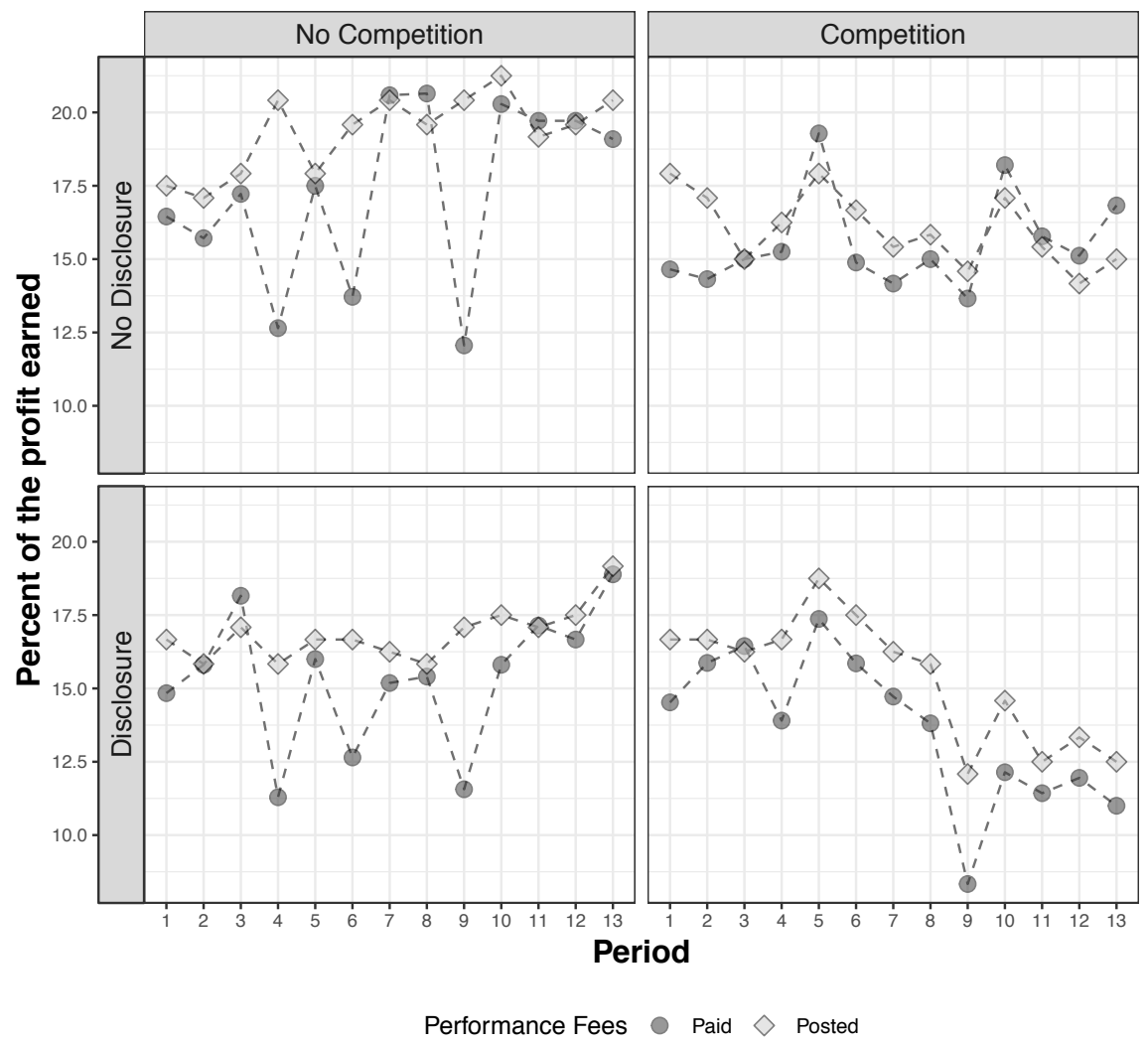

Note: For each experimental condition, diamonds show the average posted Performance Fees in a period, while dark grey circles depict the average paid Performance Fees in each period. 
Table 5. Average Performance Fees by Condition (standard deviaton in brackets).

\begin{tabular}{lll}
\hline Condition & Posted & Paid \\
\hline T1 (No Competition; No Disclosure) & $19.32(8.01)$ & $17.34(9.23)$ \\
T2 (Competition; No Disclosure) & $16.03(7.10)$ & $15.55(6.78)$ \\
T3 (No Competition; Disclosure) & $16.86(7.92)$ & $15.36(8.81)$ \\
T4 (Competition; Disclosure) & $15.35(7.85)$ & $13.64(7.36)$ \\
\hline
\end{tabular}

While we saw Management Fees strongly affected by competition, the relative changes and differences are much smaller for Performance Fees; as Figure 2 shows, Performance Fees slightly increase in No Competition, while they display a pronounced downward trend with Competition and Disclosure. As Table 5 shows, the lowest average values for posted as well as paid fees are again observed in condition T4 (Competition/Disclosure), while the highest fees are posted and paid in condition T1 (No Competition/No Disclosure).

The regression analyses presented in Table 6 (for Management Fees) and Table 7 (for Performance Fees) complement the qualitative evidence delivered by Figures 1 and 2 on the impact of treatment variables on Management and Performance Fees. The dependent variable in columns (1) and (2) is the fees posted/demanded by managers, while in columns (3) and (4) it is the fees paid by investors. The explanatory variables are given by treatment dummies and by the period of investment. An interaction between treatment variables and round of investment is introduced in models (2) and (4). 
Table 6. Management Fees' Determinants

\begin{tabular}{|c|c|c|c|c|}
\hline & PostedFee (1) & PostedFee (2) & PaidFee (3) & PaidFee (4) \\
\hline \multirow[t]{2}{*}{ (Intercept) } & $1.825^{* * *}$ & $1.539^{* * *}$ & $1.744^{* * *}$ & $1.517^{* * *}$ \\
\hline & $(0.165)$ & $(0.210)$ & $(0.172)$ & $(0.212)$ \\
\hline \multirow[t]{2}{*}{ Competition } & $-0.577^{* *}$ & -0.231 & $-0.763^{* * *}$ & -0.443 \\
\hline & $(0.176)$ & $(0.283)$ & $(0.191)$ & $(0.291)$ \\
\hline \multirow[t]{2}{*}{ Disclosure } & -0.157 & 0.144 & -0.078 & 0.034 \\
\hline & $(0.176)$ & $(0.283)$ & $(0.191)$ & $(0.291)$ \\
\hline \multirow[t]{2}{*}{ Period } & $-0.017^{* * *}$ & 0.002 & $-0.018^{* * *}$ & -0.001 \\
\hline & $(0.005)$ & $(0.008)$ & $(0.003)$ & $(0.006)$ \\
\hline \multirow[t]{2}{*}{ Comp:Disc } & & -0.147 & & -0.044 \\
\hline & & $(0.359)$ & & $(0.391)$ \\
\hline \multirow[t]{2}{*}{ Comp:Period } & & $-0.021^{*}$ & & $-0.023^{* *}$ \\
\hline & & $(0.010)$ & & $(0.007)$ \\
\hline \multirow[t]{2}{*}{ Disc:Period } & & $-0.018^{\circ}$ & & -0.007 \\
\hline & & $(0.010)$ & & $(0.007)$ \\
\hline $\mathrm{BIC}$ & 2691.839 & 2720.073 & 3758.212 & 3785.429 \\
\hline Num. obs. & 1248 & 1248 & 1936 & 1936 \\
\hline Pseudo $R^{2}$ & 0.111 & 0.115 & 0.184 & 0.185 \\
\hline
\end{tabular}

Note: Estimated outcomes of a Linear Mixed Model with random effects at the individual and session level are reported in the table.

As shown by Models (1) and (3) in Table 6, lower Management Fees are posted and paid in Competition than in No Competition, and fees decline over time. Models (2) and (4) consistently show that the declining time trend is only present in condition Competition, as the interaction term Competition:Period is the only significant factor. The impact of more disclosure is never significant and is thus overall weaker than that of competition. 
Table 7. Performance Fees' Determinants

\begin{tabular}{|c|c|c|c|c|}
\hline & PostedFee (1) & PostedFee (2) & PaidFee (3) & PaidFee (4) \\
\hline \multirow[t]{2}{*}{ (Intercept) } & $19.637^{* * *}$ & $15.785^{* * *}$ & $16.980^{* * *}$ & $10.365^{* * *}$ \\
\hline & $(1.528)$ & (1.937) & $(1.456)$ & $(1.884)$ \\
\hline \multirow[t]{2}{*}{ Competition } & -2.404 & 3.276 & -1.937 & $4.632^{\circ}$ \\
\hline & $(1.628)$ & $(2.614)$ & $(1.560)$ & $(2.522)$ \\
\hline \multirow[t]{2}{*}{ Disclosure } & -1.571 & -0.444 & -1.728 & 4.114 \\
\hline & $(1.628)$ & $(2.614)$ & $(1.560)$ & $(2.522)$ \\
\hline \multirow[t]{2}{*}{ Period } & -0.058 & $0.272^{* * *}$ & 0.028 & $0.533^{* * *}$ \\
\hline & $(0.045)$ & $(0.077)$ & $(0.041)$ & $(0.074)$ \\
\hline \multirow[t]{2}{*}{ Comp:Disc } & & 1.795 & & -0.181 \\
\hline & & $(3.312)$ & & $(3.231)$ \\
\hline \multirow[t]{2}{*}{ Comp:Period } & & $-0.506^{* * *}$ & & $-0.500^{* * *}$ \\
\hline & & $(0.089)$ & & $(0.082)$ \\
\hline \multirow[t]{2}{*}{ Disc:Period } & & $-0.156^{\circ}$ & & $-0.443^{* * *}$ \\
\hline & & $(0.089)$ & & $(0.081)$ \\
\hline $\mathrm{BIC}$ & 8257.285 & 8245.463 & 13176.104 & 13135.427 \\
\hline Num. obs. & 1248 & 1248 & 1936 & 1936 \\
\hline Pseudo $R^{2}$ & 0.048 & 0.074 & 0.032 & 0.062 \\
\hline
\end{tabular}

${ }^{* * *} p<0.001,{ }^{* *} p<0.01,{ }^{*} p<0.05,{ }^{\circ} p<0.1$

Note: Estimated outcomes of a Linear Mixed Model with random effects at the individual and session level are reported in the table.

Table 7 repeats the regressions for Performance Fees. Here we see that no factor significantly influences fees (posted as well as paid) in models (1) and (3). Only when interactions are included do we find that Performance Fees overall increase over time, but they register a net decline over time in condition Competition. Furthermore, paid fees also decline over time in condition Disclosure. The evidence on fees presented above is summarized by the following result.

Result 1 (Fees) 
a) Both Competition and Disclosure lead to lower fees, with Competition having a markedly stronger impact than Disclosure.

b) The relative impact of Competition and Disclosure is stronger for Management Fees than for Performance Fees.

\section{Investment Strategy}

Our paper does not focus on investment strategies or risk-taking, but as managers can decide on how to split any invested funds among a Stock, an Index, and a risk-free Bond, we will report how managers actually invested. It has often - and for good reason - been argued that competition between fund managers can lead to excessive risk taking. Our setting offers only limited scope for risk-taking (only three uncorrelated assets, no shorting allowed), but more risk-taking could become visible in lower fractions invested riskfree or investments overall being more concentrated on the Stock, as this asset offers the highest expected return but also the highest risk. However, we find no clear evidence of that: Figure 3 illustrates the shares managers invested into each of the three assets available (Stock, Index, Bond) in each of the four treatments. The boxplots provide a conventional representation of the quantiles of the distribution of investment choices in distinct experimental conditions. The diamond dots show the respective averages of each distribution. 
Figure 3. Investment (portfolio) choices by managers

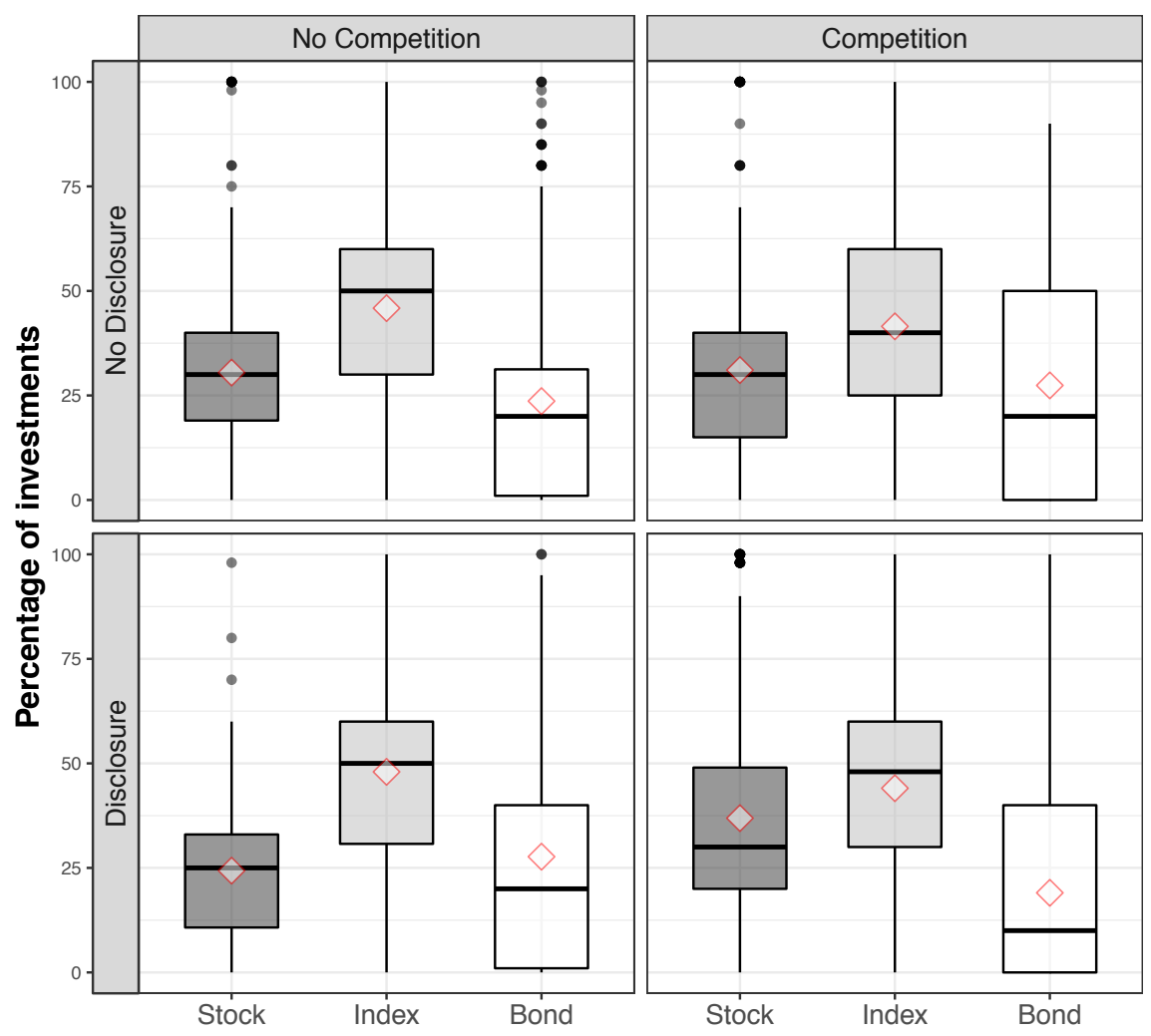

Note: Boxplots provide a conventional representation of distribution quartiles. In each panel, the dark grey boxplot shows the share of investments in Stocks, the light grey boxplot the share in Index, and the white boxplot the share in Bonds. The diamond captures mean values.

We see that the shares do not vary much; in every treatment, the largest median share is invested in the Index followed by the Stock and then the risk-free bond. Though by visual inspection the average and median fraction invested risk-free is lower in T4 than in the other three treatments, a series of non-parametric tests do not deliver any significant differences in investment choices when comparing experimental treatments. ${ }^{8}$ We thus conclude with:

\footnotetext{
${ }^{8}$ Two-sided Wilcoxon rank sum tests, significance level 5\%. All tests are computed
} 
Result 2 (Investment Strategies and Risk-taking)

Investment strategies and risk-taking are not strongly affected by Competition and Disclosure; we find no significant differences in the fractions invested in the different treatments.

\subsection{Choices by Investors}

\section{Market Participation}

In our experimental setting, investors face a trade-off between return and risk. By entrusting their endowment to a manager, they participate in the market and can (potentially) earn a higher return but also face the risk of incurring a loss. The alternative risk-free investment, however, yields only a rather low return of $1 \%$. Table 8 presents the overall share of participants who entrusted their endowment to a manager.

Table 8. Share of investors who entrusted their endowment to a manager (the remainder invested risk-free).

\begin{tabular}{|c|c|c|c|}
\cline { 3 - 4 } \multicolumn{2}{c|}{} & \multicolumn{2}{c|}{ Competition } \\
\cline { 3 - 4 } \multicolumn{2}{c|}{} & No Competition & Competition \\
\hline \multirow{3}{*}{ Disclosure } & No Disclosure & $70.0 \%$ & $86.4 \%$ \\
\cline { 2 - 4 } & Disclosure & $67.6 \%$ & $86.2 \%$ \\
\hline
\end{tabular}

We see that competition between managers-and thus more choices for investors-clearly increases market participation, as investors in Competition conditions decided to entrust their endowment to a manager in more than $86 \%$ of the cases. In No Competition conditions, a markedly lower share of investors chose a manager over the risk-free alternative $-70.0 \%$ and $67.6 \%$ in conditions No Disclosure and Disclosure, respectively.

using session-level averages. 
The regression analysis in Table 9 provides statistical support to the evidence reported above. The dependent variable is a dummy variable equal to 1 when an investor decides to entrust her/his endowment to a manager and 0 otherwise. The explanatory variables are given by the treatment dummies, the period of the investment, and controls for risk and loss aversion of the investor, as measured by the questionnaires administered at the end of the experiment.

Table 9. Investors entrusting their endowment to a manager

\begin{tabular}{lc}
\hline & Market Participation \\
\hline (Intercept) & $2.215(0.432)^{* * *}$ \\
Competition & $1.529(0.382)^{* * *}$ \\
Disclosure & $-0.134(0.348)$ \\
Period & $-0.007(0.015)$ \\
LossAversion & $0.290(0.365)$ \\
RiskAversion & $-1.219(0.362)^{* * *}$ \\
Comp:Discl & $0.063(0.527)$ \\
\hline $\mathrm{N}$ obs. & 2496 \\
$\mathrm{~N}$ SubjectID:SessionID & 192 \\
$\mathrm{~N}$ SessionID & 24 \\
\hline${ }^{* * *} p<0.001,{ }^{* *} p<0.01,{ }^{*} p<0.05,{ }^{\circ} p<0.1$
\end{tabular}

Note: Estimated outcomes of a Generalized Linear Mixed Model (Logit) with random effects at the individual and session level are reported in the table.

The regression confirms that competition between managers significantly increases investors' readiness to entrust their endowment to a manager, while different disclosure regimes do not significantly affect market participation. Higher risk aversion induces a more cautious behavior and, as a consequence, lower market participation.

Result 3 (Market Participation)

Market participation is significantly promoted by Competition but is not affected by more Disclosure. 


\section{Whom do Investors entrust with their Endowment? Distribution of Investments across Managers}

To assess the concentration of investments among managers, we first compute the ratio of entrusted endowments to a manager over total endowments entrusted. Then, as a measure of concentration, we consider the well-known Herfindahl-Hirschman Index (HHI): ${ }^{9}$ the higher the value of the index, the higher the concentration of investments.

The development of investor concentration is illustrated in Figure 4, which shows data for condition Competition, in which investors could freely choose among the four managers in their group. ${ }^{10}$

\footnotetext{
${ }^{9}$ The index is computes as $H H I=\sum_{i=1}^{N} s_{i}^{2}$, where $s_{i}$ is the market share of the $N$ competing managers. The index spans the value of minimum concentration, $H H I=1 / N$, and the monopolistic concentration value, $H H I=1$. In our setting, the minimum values are $H H I=.25$ in Competition and $H H I=.5$ in No Competition, respectively.

${ }^{10}$ In condition No Competition, investors only had the choice to entrust their funds to the one manager they were assigned to, and thus the HHI is not meaningful here.
} 
Figure 4. Concentration of investors among managers in condition Competition (HHI).

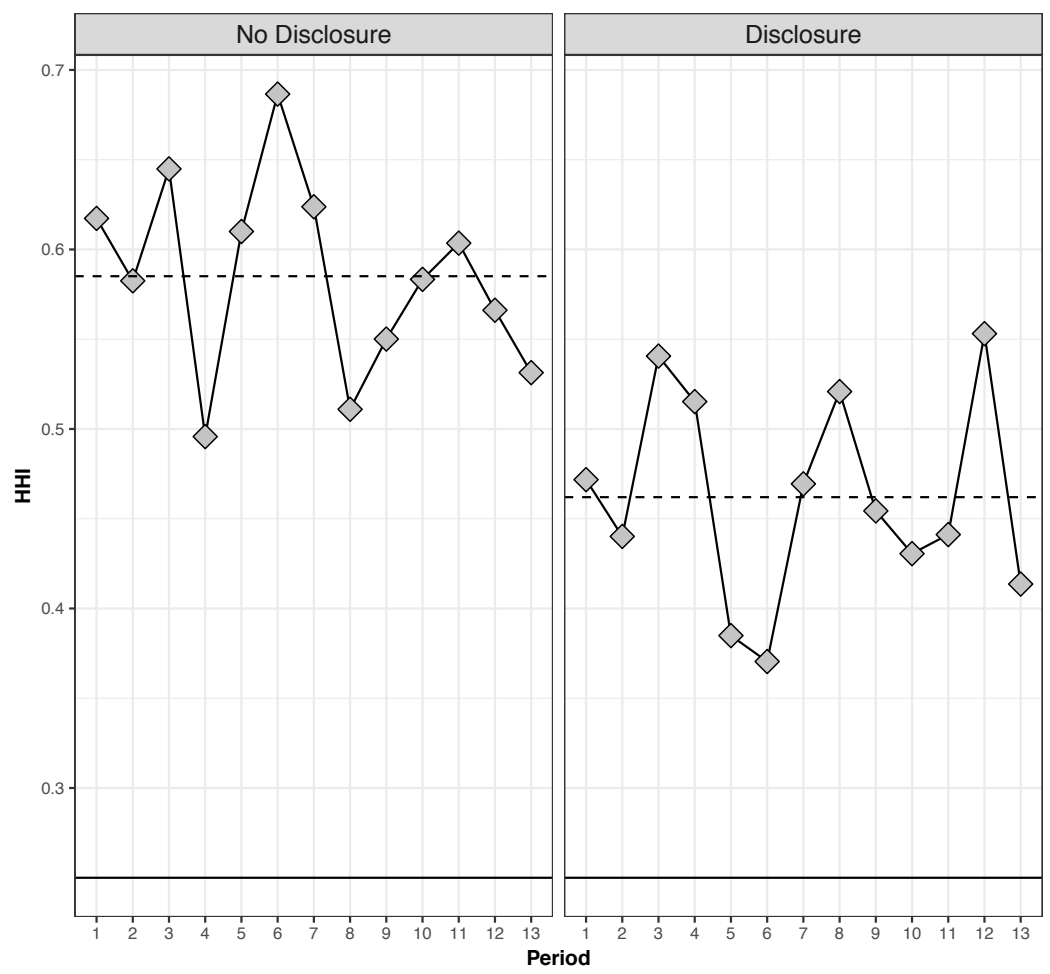

Note: In each panel, the solid horizontal line at 0.25 captures the minimal possible HHI value, the dashed lines represent the average HHI value across periods, and the diamonds the HHI value in a period.

The concentration index is always markedly above the minimally possible concentration level $(=0.25)$ in both conditions, but it is higher when there is no disclosure of fees to other managers-average values are 0.58 and 0.46 , respectively. There is no clear time trend, as values of the index in each period fluctuate around average values in both treatments. The reason for the difference between the treatments is most likely that investors, freely able to choose, largely choose the managers with lower fees. With disclosure, managers observe other managers' fees and can converge on a level considered "appropriate" by investors, while in condition No Disclosure managers do 
not observe other managers' fees and can thus not easily converge in their fee structures. To elaborate on this, we calculated the share of investors choosing the cheapest manager in their group-this number is $40.5 \%$ (36.9\%) of investors in condition No Disclosure (Disclosure). ${ }^{11}$ The respective shares for the managers with the highest fees in their group of four managers were only $10.2 \%$, irrespective of whether fees were disclosed or not.

To gain a deeper understanding of determinants of market concentration, Table 10 presents the outcome of regression analyses of potential determinants of the success of managers in attracting investors. ${ }^{12}$ Two separate regressions are presented for each condition, No Competition in models (1) and (2) and Competition in columns (3) and (4). In each regression, the dependent variable is the number of investors attracted by a manager. In models (1) and (3), we only use data from the first main period, as here all investors have the return history on all managers in their group, and we therefore include "LagReturn", i.e., the return of the preceding period (which was the last trial period), as an explanatory variable. We see that this variable is highly significant in column (1), as investors often invest if their manager had a high return the period before. With competition (column 3), the effect is also positive, but here fees play a larger role than past returns.

Models (2) and (4) use data from all 13 periods (hence the variable $P e$ riod), but here we cannot use LagReturn, as a manager who did not attract any investor in a period did not have a return data point. In model (2), we see than when investors cannot choose between managers (No Competition), only the fees demanded by their assigned manager significantly influences whether they entrust him with their endowment or not (the higher the fees, the less likely), while fees by other managers (which they see but cannot select) have no significant impact. This is different in condition Competition (see column (4)), where higher own-fees lower the probability of attracting

\footnotetext{
${ }^{11}$ The "cheapest manager" is defined as a manager who is cheaper than all other managers in at least one fee and not more expensive than any of the other managers in the other fee.

${ }^{12}$ Only the count part of the Zero-Inflated Poisson model is reported here. The full model estimate is presented in the Appendix D with the outcomes of a robustness check.
} 
Table 10. Factors determining whether a manager succeeds in attracting investors

\begin{tabular}{lclll}
\hline & No Competition $(1)$ & No Competition $(2)$ & Competition $(3)$ & Competition (4) \\
\hline Intercept & $2.519(0.531)^{* * *}$ & $1.800(0.192)^{* * *}$ & $0.682(1.243)$ & $1.075(0.221)^{* * *}$ \\
Disclosure & $0.024(0.181)$ & $-0.064(0.088)$ & $-0.085(0.272)$ & $-0.273(0.077)^{* * *}$ \\
Period & & $-0.006(0.006)$ & & $-0.011(0.010)$ \\
OwnManFee & $-0.057(0.104)$ & $-0.093(0.028)^{* *}$ & $-0.251(0.171)$ & $-0.347(0.056)^{* * *}$ \\
OwnPerfFee & $0.000(0.013)$ & $-0.006(0.003)^{\circ}$ & $-0.041(0.020)^{*}$ & $-0.022(0.005)^{* * *}$ \\
OthManFee & $-0.532(0.178)^{* *}$ & $0.011(0.051)$ & $0.420(0.354)$ & $0.232(0.067)^{* * *}$ \\
OthPerfFee & $-0.027(0.022)$ & $-0.001(0.006)$ & $0.027(0.046)$ & $0.024(0.007)^{* *}$ \\
LagReturn & $0.053(0.012)^{* * *}$ & & $0.022(0.018)$ & \\
\hline N. Obs & 48 & 624 & 624 \\
\hline${ }^{* * *} p<0.001,{ }^{* *} p<0.01,{ }^{*} p<0.05,{ }^{\circ} p<0.1$ &
\end{tabular}

Note: Estimated outcomes of a Generalized Mixed Model (Zero-inflated Poisson) with random effects at the individual and session level are reported in columns (2) and (4). Estimated outcomes of a Zero-inflated Poisson model are reported in columns (1) and (3). Only the count component is reported here, while the full model estimate is reported in Appendix D.

investors, while higher fees by competing managers increase a manager's number of investors. This holds for Management as well as Performance Fees, with the effect being stronger for the the former than for the latter.

Result 4 (Market Concentration)

a) When allowed to freely choose their manager, investors mostly select managers with lower fees, especially when disclosure is weak.

b) In markets with competition between managers, the higher the fees applied by competitors, the more investors a manager attracts; this decreases with higher own-fees.

c) In markets without competition, the ability to attract investors is significantly affected only by own fees.

\subsection{Earnings of Investors and Managers}

To conclude our data analysis, Figure 5 provides a representation of average earnings for investors and managers in our four experimental conditions. In each panel, the left bar shows average earnings of all participants, while the right bar depicts average earnings of only those participants who are active 
in the market. Accordingly, the right bar only considers data from periods when a manager attracted investors and investors decided to entrust their funds to a manager.

Figure 5. Earnings of Investors and Managers.

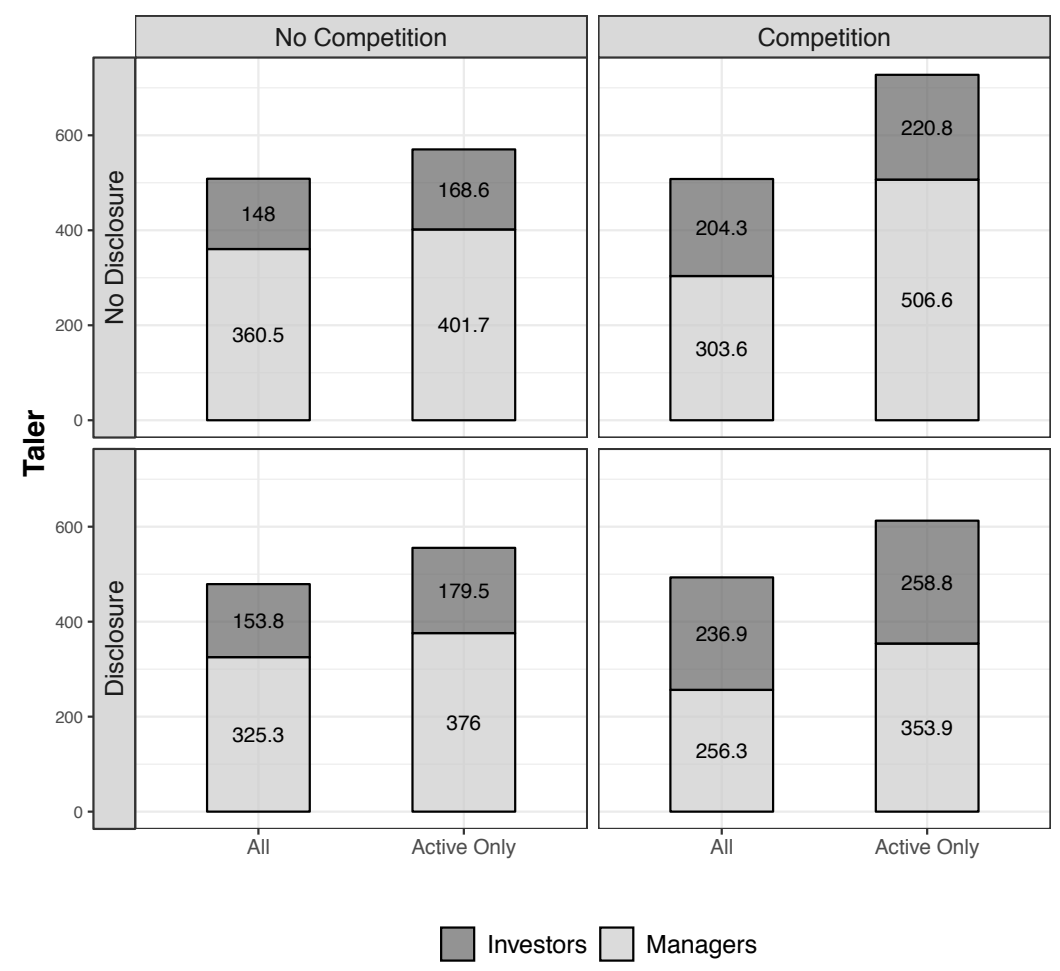

Note: In each panel, the bar on the left shows overall average earnings of managers and investors; the bar on the right shows earnings of investors who entrusted their endowment to a manager and of managers who attracted at least one investor.

As shown by Figure 5, when considering all participants, an increase in Competition and Disclosure leads to a decrease in average earnings among the managers and to a proportional increase in average earnings of the investors with the totals almost unchanged. A series of non-parametric tests ${ }^{13}$ shows that there is a statistically significant difference in average earnings

\footnotetext{
${ }^{13}$ Two-sided Wilcoxon rank sum tests, significance level 5\%. All tests are computed using individual-level averages.
} 
Table 11. Earnings of investors and managers

\begin{tabular}{|c|c|c|c|c|}
\hline & Investors (1) & Investors (2) & Managers (1) & Managers (2) \\
\hline (Intercept) & $\begin{array}{c}86.671 \\
(86.036)\end{array}$ & $\begin{array}{c}40.707 \\
(133.862)\end{array}$ & $\begin{array}{l}432.126^{* * *} \\
(56.450)\end{array}$ & $\begin{array}{l}276.732^{* * *} \\
(79.053)\end{array}$ \\
\hline Competition & $\begin{array}{c}68.962 \\
(67.003)\end{array}$ & $\begin{array}{c}156.001 \\
(159.830)\end{array}$ & $\begin{array}{c}20.012 \\
(49.492)\end{array}$ & $\begin{array}{c}301.388^{* *} \\
(104.164)\end{array}$ \\
\hline Disclosure & $\begin{array}{c}23.616 \\
(66.968)\end{array}$ & $\begin{array}{c}3.185 \\
(159.613)\end{array}$ & $\begin{array}{c}-68.753 \\
(49.452)\end{array}$ & $\begin{array}{c}34.507 \\
(101.771)\end{array}$ \\
\hline Period & $\begin{array}{c}5.713 \\
(4.829)\end{array}$ & $\begin{array}{c}9.714 \\
(8.748)\end{array}$ & $\begin{array}{c}-0.895 \\
(2.870)\end{array}$ & $\begin{array}{r}9.418^{*} \\
(4.719)\end{array}$ \\
\hline Comp:Disc & & $\begin{array}{c}24.041 \\
(137.057)\end{array}$ & & $\begin{array}{l}-84.052 \\
(100.193)\end{array}$ \\
\hline Disc:Period & & $\begin{array}{c}0.633 \\
(9.662)\end{array}$ & & $\begin{array}{c}-4.733 \\
(5.722)\end{array}$ \\
\hline Comp:Period & & $\begin{array}{c}-7.623 \\
(9.751)\end{array}$ & & $\begin{array}{c}-18.221^{* *} \\
(5.774)\end{array}$ \\
\hline $\mathrm{BIC}$ & 31391.417 & 31389.051 & 14024.022 & 14011.359 \\
\hline Num. obs. & 1936 & 1936 & 963 & 963 \\
\hline Pseudo $R^{2}$ & 0.003 & 0.003 & 0.009 & 0.020 \\
\hline
\end{tabular}

Note: Estimated outcomes of a Linear Mixed Model with random effects at the individual and session level are reported in the table. The estimates are restricted to managers and investors active in the market.

for managers and for investors when comparing No Competition/No Disclosure and Competition/Disclosure. A significant difference is also observed when comparing, for managers, No Competition/No Disclosure and Competition/No Disclosure and, for investors, No Competition/Disclosure and Competition/Disclosure.

When focusing only on active participants (investors who entrusted their endowment to a manager and managers who attracted at least one investor), an increase in competition leads to higher earnings both for managers and investors when there is no disclosure of fees to other managers, and an increase for investors associated with a moderate decrease for managers when fees are disclosed. Competition leads to higher overall earnings as more investors participate in the market, while Disclosure had little effect. A series of nonparametric tests highlights no significant differences in managers' earnings across experimental conditions. By contrast, investors' earnings are positively affected by competition: a significant difference is observed between 
condition Competition/Disclosure and conditions No Competition/No Disclosure and No Competition/Disclosure.

When we look at the composition of managers' earnings, i.e., which fractions of earnings they derive from Management and from Performance Fees, we see a clear pattern: in condition No Competition, i.e., T1 and T3, the larger share of earnings is derived from Management Fees, while these fees are lower in condition Competition, where the larger part of earnings comes from Performance Fees. Table 12 provides the respective numbers.

Table 12. Average Earnings of Managers from Managerment, respectively Performance Fees by Condition.

\begin{tabular}{lll}
\hline Condition & Management Fee & Performance Fee \\
\hline T1 (No Competition; No Disclosure) & 232.1 & 169.6 \\
T2 (Competition; No Disclosure) & 220.3 & 286.3 \\
T3 (No Competition; Disclosure) & 223.0 & 153.0 \\
T4 (Competition; Disclosure) & 153.5 & 200.3 \\
\hline
\end{tabular}

\section{Result 5 (Earnings)}

a) When we look at earnings overall, more competition favors investors and is detrimental to managers.

b) Among participants active in the market, more Competition leads to better outcomes for investors and does not significantly affect managers' earnings.

c) Without Competition managers derive most of their earnings from performanceindependent Management Fees, while with competition the larger share comes from Performance Fees.

\subsection{Conclusion}

In this paper we explored the influence of two crucial variables in markets that can be influenced by regulators: (i) Competition between managers and (ii) Disclosure of fees among fund managers. We experimentally investigated whether and to what extent these two variables affect fees, investment 
strategies, market participation, and earnings of investors and managers. We found that more competition between managers lead to a significant reduction of fees, the effect being stronger for Competition than for Disclosure. Furthermore, the relative decrease was larger for Management Fees than for Performance Fees. The decrease in fees does not affect managers' investment strategies, but increases market participation by investors. Overall, higher competition leads to a shift in profits from managers to investors, although for successful managers, i.e., those able to attract investors, competition leads to an increase in earnings.

We add to the empirical literature about the impact of competition on the fees paid by investors to access fund management services. In line with economic intuition, we show that lower fees characterize environments with more competition between managers and more information available to managers about their competitors.

Allen and Gale (2004) argue that banks facing stronger market competition may take on extra risk as a reaction to the loss in monopoly rent. This argument could be easily extended to fund management, and the incentive to take on extra risk may even be magnified by the "limited liability" embedded in Performance Fees. However, in our setting, fiercer competition, with the loss of monopoly rent, does not induce a significant change in the riskiness of investments by managers. Thus, managers seem not to try to compensate for the loss in fees with investments delivering, on average, higher returns. This results is even more remarkable when considering that the strategies of managers are always private information and are not disclosed to investors or other managers.

The stronger impact of competition on Management Fees than on Performance Fees may be due to the behavioral phenomenon that fees paid on performances are codified as foregone gains, while fees paid on capital invested are codified as losses. If this is the case, Prospect Theory (Tversky and Kahneman, 1992) suggests that the psychological impact of the latter is stronger than that of the former because of loss aversion. However, the detailed understanding of differences in the perception of Management and Performance fees goes beyond the scope of the present investigation and de- 
serves further attention.

The lower fees observed under competition encourage market participation by investors. In light of the homogeneity of investment strategies across conditions, the driving factor for market participation seems to be the price asked for financial intermediation. We show that managers applying lower fees than their competitors are more likely to attract investors. From this we conclude that lower fees are a key factor in encouraging market participation. This fits nicely with empirical evidence showing that investors often perceive fees as too high (Linciano et al., 2016). Encouraging market participation via fee competition may have important implications for the growth of financial markets and for the real economy. Regulators can encourage this by ensuring competition between managers and disclosure of fees and performances.

Finally, competition in the form of allowing investors to choose among several fund managers leads to a transfer of earnings from managers to investors when considering the entire population. However, when focusing only on managers who attracted investors, competition leads to higher earnings for both managers and investors. On the one hand, competition operates as a selection process favoring managers who are willing to lower their fees, especially their Management Fees. On the other hand, competition increases the pool of resources managed. Thus, managers do not face a simple zero-sum game.

With reference to the ongoing debate on the effects competition has on markets, our results suggest that more competition helps achieve better outcomes in terms of higher market participation and lower fees. This benefits both investors and managers able to attract investors. This is a relevant result: while there is an extensive literature arguing that a competitive environment may lead to unwanted outcomes, our results suggest mostly otherwise. 


\section{References}

Allen, F. (2001). Do financial institutions matter? The Journal of Finance, $56(4): 1165-1175$.

Allen, F. and Gale, D. (2004). Competition and financial stability. Journal of Money, Credit and Banking, pages 453-480.

Bebchuk, L. A. and Spamann, H. (2009). Regulating bankers' pay.

Broeders, D., van Oord, A., and Rijsbergen, D. R. (2017). Does it pay to pay performance fees? empirical evidence from dutch pension funds.

Christoffersen, S. E. and Musto, D. K. (2002). Demand curves and the pricing of money management. The Review of Financial Studies, 15(5):1499-1524.

Coates, J. C. and Hubbard, R. G. (2007). Competition in the mutual fund industry: Evidence and implications for policy. J. Corp. L., 33:151.

Eckel, C. C. and Grossman, P. J. (2008). Men, women and risk aversion: Experimental evidence. Handbook of experimental economics results, 1:10611073.

Elton, E. J., Gruber, M. J., and Blake, C. R. (2003). Incentive fees and mutual funds. The Journal of Finance, 58(2):779-804.

Falk, A., Becker, A., Dohmen, T. J., Enke, B., and Huffman, D. (2015). The nature and predictive power of preferences: Global evidence.

Fischbacher, U. (2007). z-tree: Zurich toolbox for ready-made economic experiments. Experimental economics, 10(2):171-178.

Gil-Bazo, J. and Ruiz-Verdú, P. (2009). The relation between price and performance in the mutual fund industry. The Journal of Finance, 64(5):21532183.

Gorton, G. and Winton, A. (2003). Financial intermediation. In Handbook of the Economics of Finance, volume 1, pages 431-552. Elsevier. 
Grinblatt, M. and Titman, S. (1989). Adverse risk incentives and the design of performance-based contracts. Management science, 35(7):807-822.

Kritzman, M. P. (1987). Incentive fees: Some problems and some solutions. Financial Analysts Journal, 43(1):21-26.

Lack, S. (2012). The hedge fund mirage: The illusion of big money and why it's too good to be true. Wiley.

Linciano, N., Gentile, M., and Soccorso, P. (2016). Report on financial investments of italian households. behavioural attitudes and approaches2016 survey.

Malkiel, B. G. (2013). Asset management fees and the growth of finance. Journal of Economic Perspectives, 27(2):97-108.

Parida, S. and Tang, Z. (2017). Price competition in the mutual fund industry. Economic Modelling.

Rajan, R. G. (2006). Has finance made the world riskier? European Financial Management, 12(4):499-533.

Stracca, L. (2006). Delegated portfolio management: A survey of the theoretical literature. Journal of Economic Surveys, 20(5):823-848.

Thanassoulis, J. (2012). The case for intervening in bankers' pay. The Journal of Finance, 67(3):849-895.

Tversky, A. and Kahneman, D. (1992). Advances in prospect theory: Cumulative representation of uncertainty. Journal of Risk and uncertainty, $5(4): 297-323$.

Van Rooij, M., Lusardi, A., and Alessie, R. (2011). Financial literacy and stock market participation. Journal of Financial Economics, 101(2):449472. 


\section{Appendix}

\section{A General instructions}

[Instructions are for Competition + Disclosure. When there are changes for the other conditions, the text will be reported in italic.]

\section{Welcome!}

You are going to take part on a study investigating economic decision making.

Please do not talk to other participants during the experiment, otherwise you will be excluded from the experiment without being paid. All data will be collected anonymously: your identity will never be revealed to the other participants.

For any questions about the instructions or during the experiment, please raise your hand and we will answer your questions privately.

\section{General Instructions}

You will be randomly assigned in one of two groups: INVESTORS and MANAGERS. There are two times as many INVESTORS as MANAGERS.

No Competition: Every manager will be randomly matched with two investors and the group composition will remain the same for the main part of the experiment. Investors will be informed about the label of the manager in the same group at the beginning of the experiment.

The experiment will run for a number of periods between 10 and 25. The exact number of periods have been defined before the experiment started, but it will not be announced in advance. In each period you will be asked to make decisions according to the rules we will explain later. 
During the experiment the experimental currency you will use is Taler, and, at the end of the experiment, the amount of Taler you will have earned will be converted in Euro according to the rule 200 Taler $=1$ Euro. In addition to the earnings of the main part of the experiment, you will receive 3 Euro for your punctual attendance. The entire payment will be paid out in cash and privately after the experiment.

INVESTORS get an endowment each period (10.000 Taler=experimental currency) and have to decide whether to entrust this endowment to a MANAGER.

No Competition : INVESTORS get an endowment each period (10.000 Taler=experimental currency) and have to decide whether to entrust this endowment to the MANAGER or not.

If the INVESTOR entrusts the money s/he has to pay a management fee to the MANAGER. The MANAGER has to make an investment decision each period: s/he has to decide how much to invest in the stock index, an individual stock and risk-free bonds ( see Table 13).

Table 13. Characteristics of the financial tools

\begin{tabular}{|c|c|c|}
\hline & $\mu$ & $\sigma$ \\
\hline Individual Stock & $6 \%$ & $20 \%$ \\
\hline Index & $5 \%$ & $10 \%$ \\
\hline Risk free bond & $1 \%$ & $0 \%$ \\
\hline
\end{tabular}

The three investments differ in terms of expected returns $(\mu)$, with the individual stock providing a higher expected return $(6 \%)$, followed by the index $(5 \%)$ and by the bond (1\%). The three investments differ also in terms of standard deviation $(\sigma)$, with the individual stock characterized by the highest standard deviation (20\%), followed by the index (10\%) and by the bond $(0 \%)$.

The $\mu$ parameter is a measure of investment profitability, while the $\sigma$ parameter is a measure of risk of the investment. For the three sources of investment described above, a higher profitability correspond to a higher risk. 
Furthermore, the returns of the individual stock and those of the index are not correlated, namely, they are independent random draws.

If the investor decides to not entrust the money to the manager, s/he earns the risk-free return of $1 \%$.

Participants acting as portfolio managers are master students in finance with experience and knowledge about portfolio management. They also have some training periods to get acquainted with the investment decision at hand. Results of training periods are not relevant for the final payment.

\section{Detailed instructions for MANAGERS}

In each period, the management of the portfolio entitles the manager to a management fee $M$ (a percentage of the initial value of the endowment), plus a performance fee $\mathrm{P}$, which is calculated as a percentage on the realized returns (final value of the investment minus initial value of the endowment) in every period. More precisely, the 16 possible combinations of the fees are:

Table 14. Combination of fees $(\mathrm{M}+\mathrm{P})$

\begin{tabular}{|c|c|c|c|c|}
\hline \multirow{2}{*}{$\begin{array}{c}\text { Performance fee (P) } \\
\text { (\% of profits) }\end{array}$} & \multicolumn{4}{|c|}{$\begin{array}{c}\text { Management fee (M) } \\
\text { (\% of endowment) }\end{array}$} \\
\cline { 2 - 5 } & $\mathbf{0 \%}$ & $\mathbf{1 \%}$ & $\mathbf{2 \%}$ & $\mathbf{3 \%}$ \\
\hline $\mathbf{0 \%}$ & $0 \%-0 \%$ & $0 \%-1 \%$ & $0 \%-2 \%$ & $0 \%-3 \%$ \\
\hline $\mathbf{1 0 \%}$ & $10 \%-0 \%$ & $10 \%-1 \%$ & $10 \%-2 \%$ & $10 \%-3 \%$ \\
\hline $\mathbf{2 0 \%}$ & $20 \%-0 \%$ & $20 \%-1 \%$ & $20 \%-2 \%$ & $20 \%-3 \%$ \\
\hline $\mathbf{3 0 \%}$ & $30 \%-0 \%$ & $30 \%-1 \%$ & $30 \%-2 \%$ & $30 \%-3 \%$ \\
\hline
\end{tabular}

Participants acting as managers, at the beginning of every period, will be asked to decide the composition of the payment structure they ask for the management of the portfolio, by selecting one of the 16 possible combinations of $\mathrm{M}$ and $\mathrm{P}$. This information will then be provided to INVESTORS who will decide whether and to whom to entrust their endowment.

The performance fee $(\mathrm{P})$ will be allocated only if a positive profit is realized (and zero otherwise), while the management fee (M) will be paid independently of the realized profit. 
A manager may have more than one investor entrusting him the endowment. After receiving all endowments, the manager decides on the percentages of wealth to invest in each financial tool (see Table 13).

The MANAGER is free to choose any strategy s/he considers appropriate with the only condition that the investment decisions have to sum to $100 \%$ of the endowment in each period.

Once all investment decisions have been made, MANAGERS will see the own return on investment before and after the fees $(\mathrm{M}+\mathrm{P})$ are deducted.

Before starting the main periods, 6 training periods will be conducted: during these periods your strategies will not be revealed, but, starting with period 4 the returns will be shown to INVESTORS and to other MANAGERS.

No Disclosure: Before starting the main periods, 6 training periods will be conducted: during these periods your strategies will not be revealed, but, starting with period 4 the returns will be shown only to INVESTORS.

For these training periods the endowment every manager will have is 1.000 Taler.

The main tables you will find on your screen will look like the one bellow:

\section{Detailed instructions for INVESTORS}

At the beginning of every period, participants acting as INVESTOR will be endowed with 10.000 Taler. After the fees ( $\mathrm{M}$ and $\mathrm{P}$ ) and the returns of the last investment decision made by all MANAGERS will be shown, the INVESTORS will be asked to decide whether and to whom to entrust the $100 \%$ endowment.

NO Competition : After the fees ( $M$ and $P$ ) and the returns of the last investment decision made by all managers will be shown, the investors will be asked to decide whether entrust the $100 \%$ endowment to the manager or 


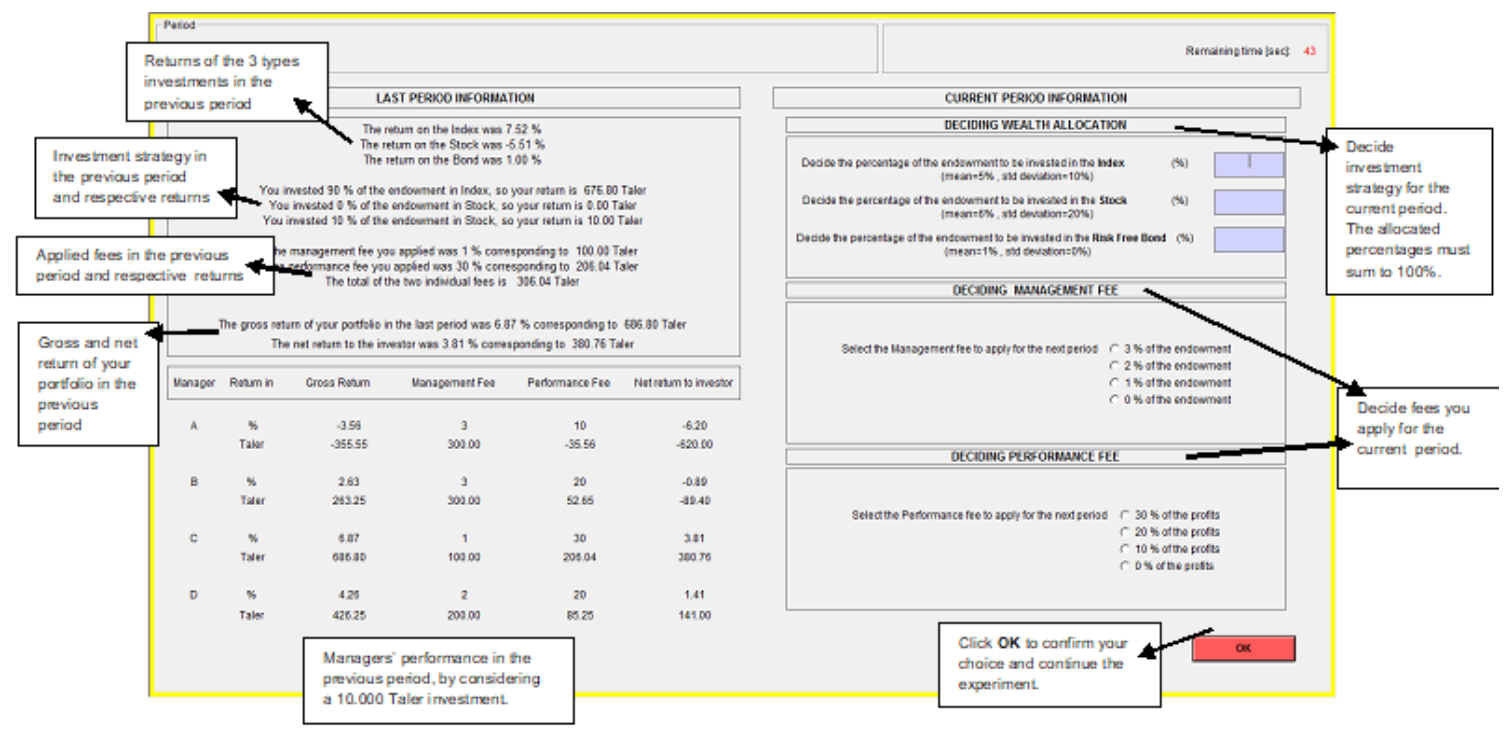

Figure 6. Example of managers' decisional screen: Disclosure

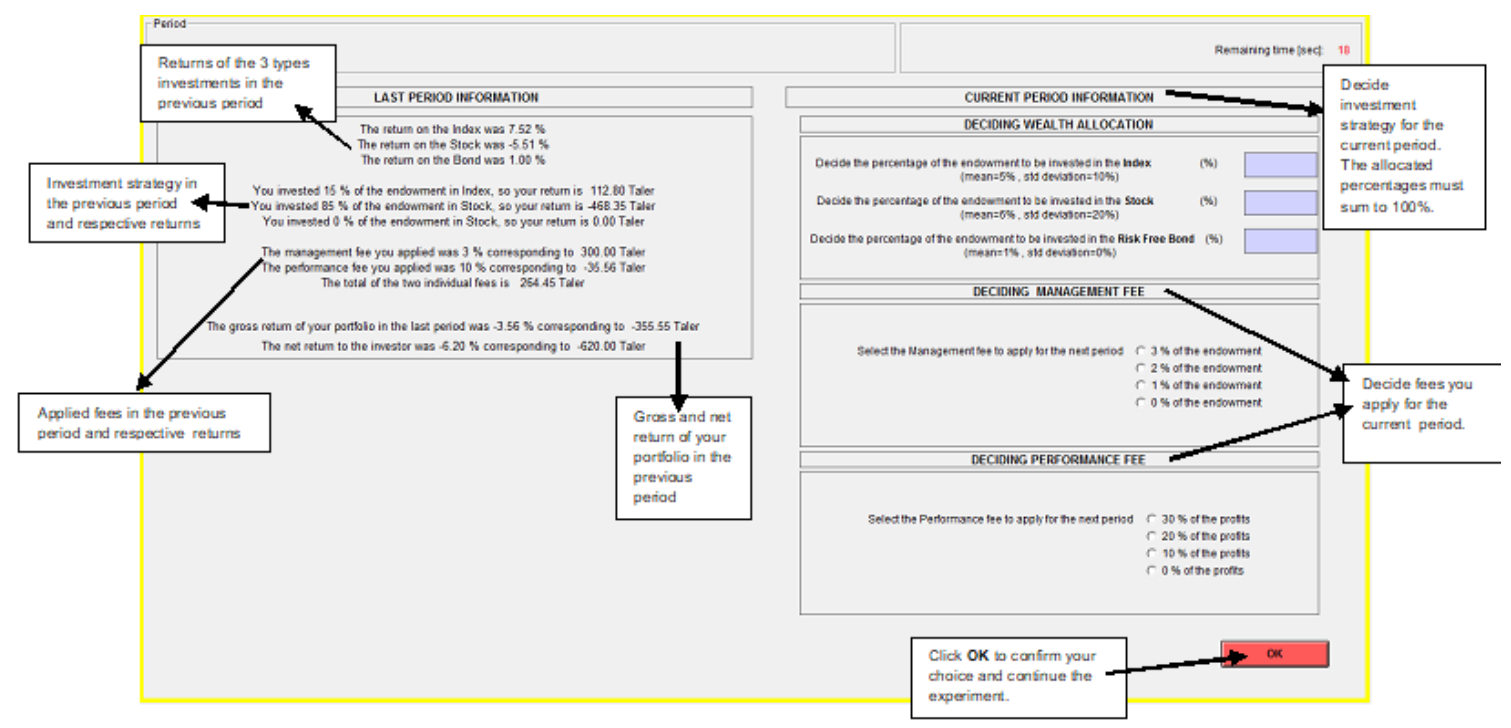

Figure 7. Example of managers' decisional screen: No Disclosure

not.

If an INVESTOR does not want to entrust his endowment to any of the MANAGERS, the endowment is deposited on a separate account, and the return of the investment will be $1 \%$, which is the risk free interest rate. 
The main tables you will find on your screen will look like the one bellow:

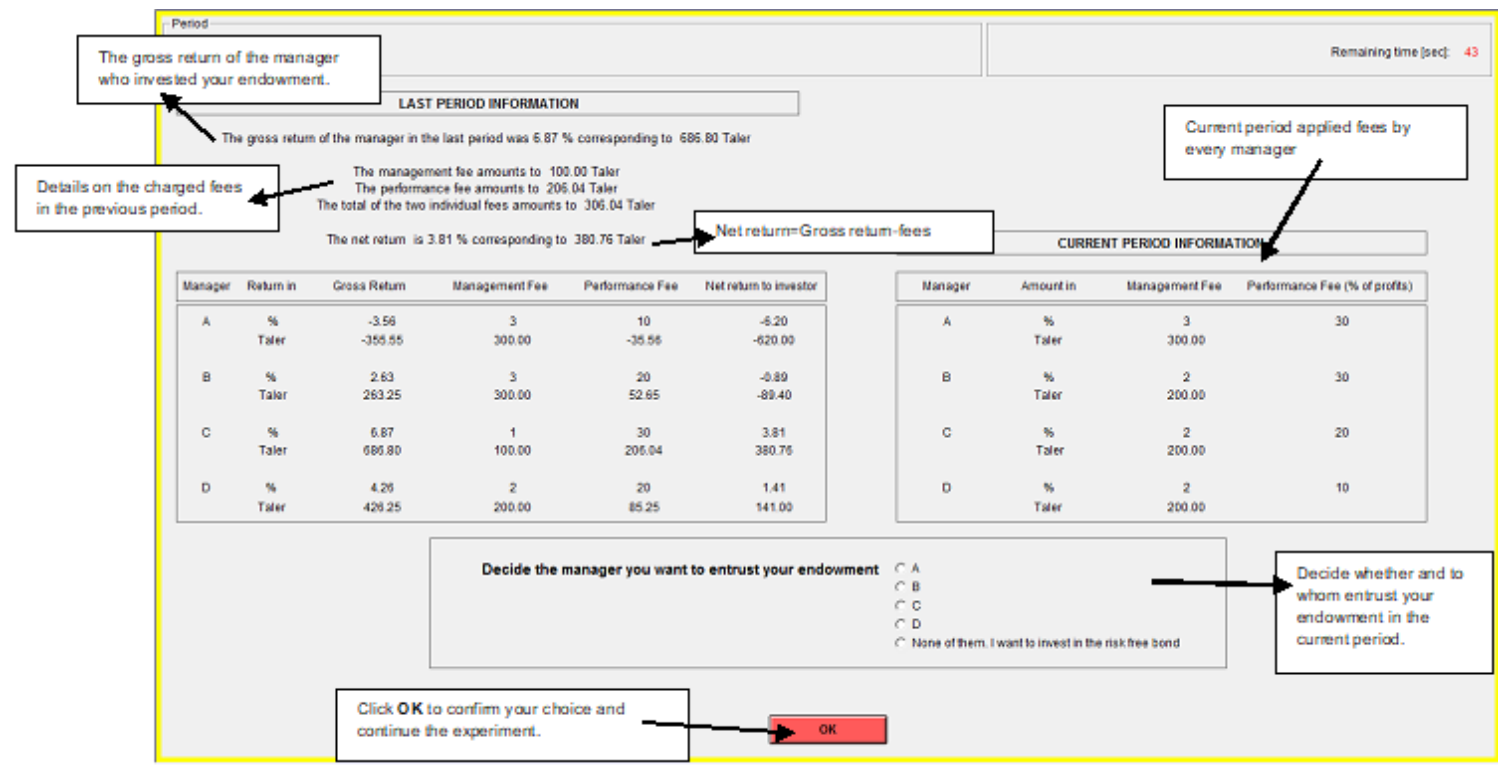

Figure 8. Example of investors' decisional screen: Competition

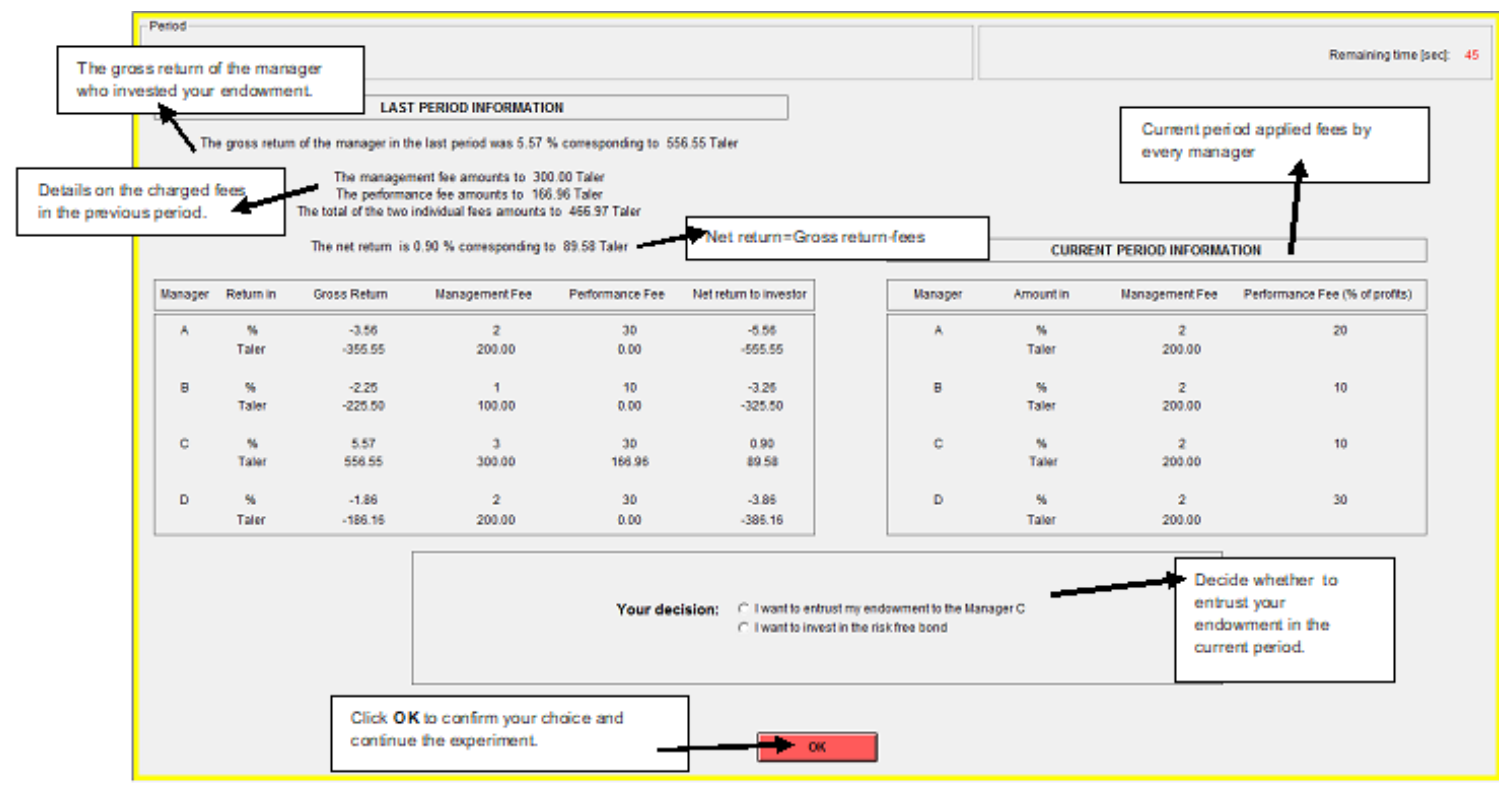

Figure 9. Example of investors' decisional screen: No Competition 


\section{Payment}

Both the INVESTORS and the MANAGERS will be paid on profits. Here are some examples of possible investment returns:

- Suppose an investor handed his endowment to a manager who demands $1 \%$ management fee and $10 \%$ performance fee. The manager invests and generates $5 \%$ profit. The investment thus grows from 10.000 to 10.500 Taler. The manager receives $1 \%$ of $10.000=100$ plus $10 \%$ of profits $(500)=50$ for a total of 150 Taler. The investor receives the profit of 500 minus the fees $(150)=350$ Taler.

- Suppose that the demanded management fee was $2 \%$ and $20 \%$ of performance fee. The manager invests and generates a $7.2 \%$ profit, meaning that investment grows from 10.000 to 10.720 Taler. The manager thus receives $2 \%$ of $10.000=200$ plus $20 \%$ of $720=144$, for a total of 344 Taler. The investor receives the profit (720) minus the fees $(344)=376$ Taler.

- Suppose that the demanded fees were $2 \%$ of management fee and $10 \%$ of performance fee. The manager invests and generates a $-2.5 \%$ return, meaning that the investment decreases from 10.000 to 9.750 . The managers receives $2 \%$ of $10.000=200$, and no performance fee. The investor receives the profit $(-250)$ minus the fees $(200)$, for a total loss of -450 .

At the end of the experiment the payment of both INVESTORS and MANAGERS will be the sum of 3 randomly drawn realizations from the main periods. Suppose that the 3 realizations are examples above, thus:

- the payment of the MANAGER:

- if only one INVESTOR entrusts the own endowment, the payment of the MANAGER will be $150+344+200=694$ Taler;

- if two INVESTORS entrusted their endowments the payment will amount to $\left(2^{*} 150\right)+\left(2^{*} 344\right)+(2 * 200)=1388$ Taler; 
- if none of the INVESTORS entrusted their endowments, the respective MANAGER will get 0 (zero) Taler.

- the payment of the INVESTOR:

- amounts to $350+376+(-450)=276$ Taler if $\mathrm{s} /$ he entrusted the own endowment to the MANAGER;

- amounts to $100+100+100=300$ Taler if $\mathrm{s} /$ he decided to invest in the Bond and get the risk free interest rate $(1 \%)$.

Details about your payment for the investment task will be provided only at the end of the experiment, and not immediately after the investment task finishes.

During the experiment, participants acting as investors may incur losses. In that case, the loss must be recovered by performing a task in the laboratory at the end of the experiment. More precisely, participants who will register a loss will be asked to count the number of values equal to 1 in a table containing values from 1 to 9 . For every correctly counted table you will obtain a loss compensation of 200 Taler. Once the participant will finish to correctly count the necessary number of tables, s/he can leave the laboratory. For example, if the loss was 530 Taler, the participant will have to correctly count 3 tables before leaving the room.

\section{Other possible earnings}

Once the main experiment is finished, each participant, independently of the previously assigned role, will be asked to (individually) make decisions which are relevant for the (own) final payment. In one of these tasks, you will be asked to choose between possible prospects. At the end of this phase, one of the selected (by you) prospects will be randomly chosen to be implemented, and the respective outcome will be added to your final payment. If the outcome of the selected prospect to be paid will be negative amount (a loss), the respective amount will be deducted from the 3 ? participation payment. 
After this task, you will be asked to correctly answer to some questions. One of the questions will be randomly selected, and, if the answer you provided will be found to be correct, we will add to your final payment 200 Taler and zero otherwise. The experiment concludes with a short questionnaire.

If there are no questions, we can start the experiment. 


\section{B Risk elicitation task}

\section{B.1 Loss domain}

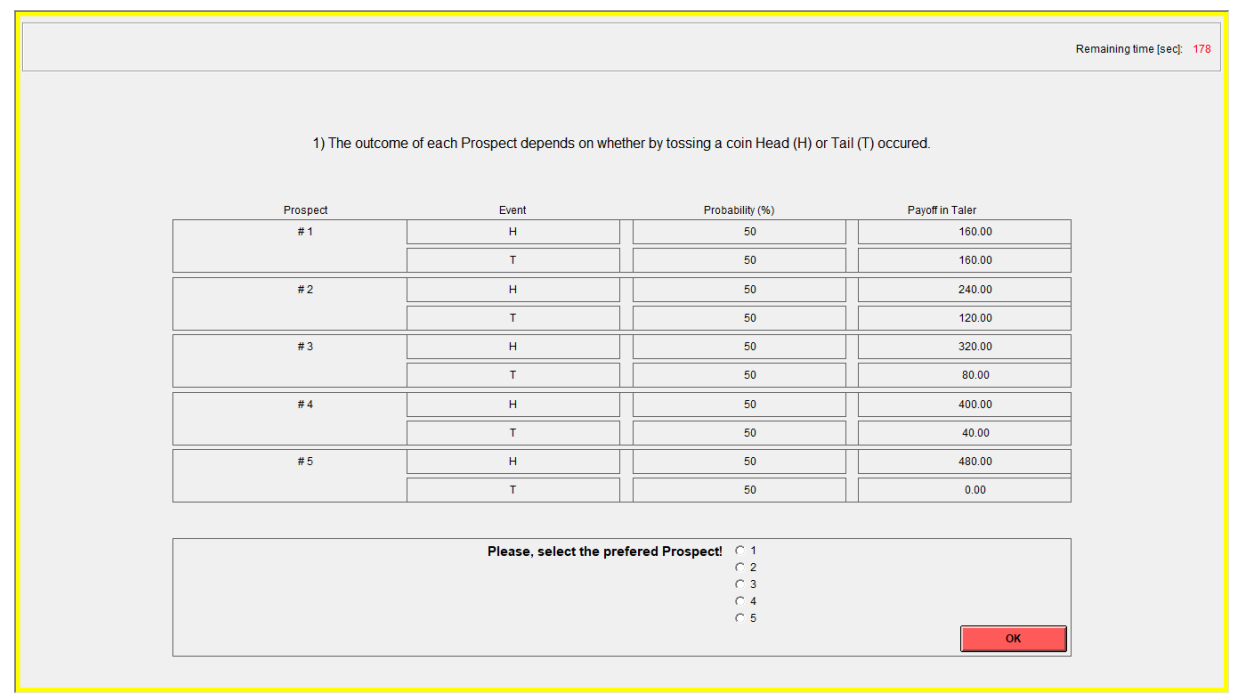

B.2 No-loss domain

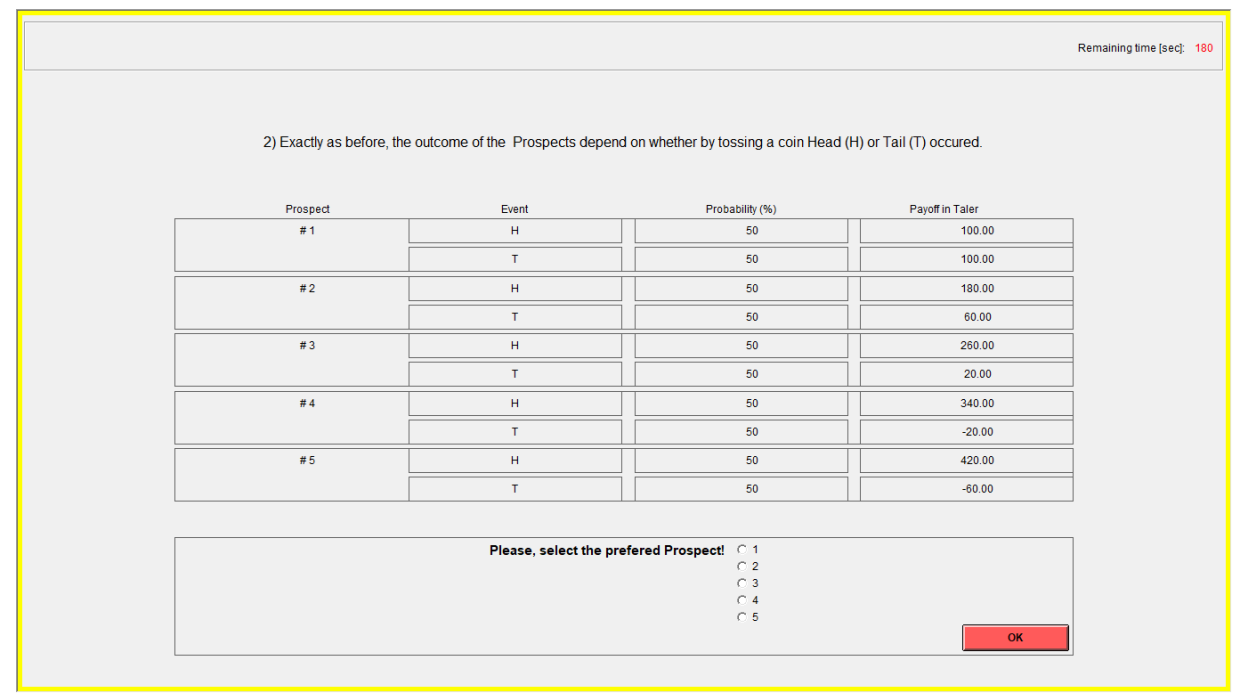




\section{Questionnaire}

\section{C.1 Financial literacy questionnaire}

1. Suppose you have $100 €$ deposited in a bank account which remunerates your savings at an annual rate of $2 \%$. After 5 years how many $€$ you will have in your bank account if you leave your money deposited?
(a) More than 102
(b) Exactly 102
(c) Less than 102
(d) I don't know

2. Suppose you have $100 €$ deposited in a bank account which remunerates your savings at an annual rate of $20 \%$, and suppose you do not withdraw from your bank account liquidity nor interest. After 5 years how many $€$ you will have you been collected in your account?
(a) More than 200
(b) Exactly 200
(c) Less than 200
(d) I don't know

3. Which of the following statements is true? If somebody buys the stock of firm B in the stock market ...
(a) s/he owns part of firm B.
(b) s/he has lent money to company B.
(c) $\mathrm{s} /$ he is liable for firm's B debts.
(d) None of the above
(e) Do not know

4. Considering a long period investment (e.g. 10 or 20 years) which asset normally gives the highest return? 

(a) Savings accounts
(b) Bonds
(c) Stocks
(d) Do not know

5. The stocks are usually more risky than bonds.
(a) True
(b) False
(c) I don't know

6. If the interest rate falls, what should happen to bond prices?
(a) Rise
(b) Fall
(c) Stay the same
(d) None of the above
(e) I don't know

\section{C.2 Additional questions to check the basic financial knowledge}

1. Do you know the meaning of the term "standard deviation"?
(a) YES
(b) NO

2. Given two lotteries, $\mathbf{L}$ and $\mathbf{G}$, which one has a higher standard deviation?

- L: 20 Euro with probability $60 \%$ and 10 Euro with probability $40 \%$.

- G: 22 Euro with probability $60 \%$ and 7 Euro with probability $40 \%$ 
$\Longrightarrow$ Your answer:

- $\mathrm{L}$

- $\mathrm{G}$

- They have the same standard deviation

- I do not know.

\section{Count Models}

Table 15 complements the information presented in Table 10, by considering both the Count part (upper panel) and the Zero part (lower panel) of the estimated zero-inflated Poisson models. This model was chosen to account for i) the count nature of the dependent variable (number of investments attracted) and ii) the large fraction of zeroes in the dependent variable (11.9\% in No Competition and $33.8 \%$ in Competition).

In the main text of the paper only the Count part of the model is reported (see Table 15). This refers to the (positive) count process, i.e. the number of investments attracted. Here, we present also the the Zero part, capturing the "excess zeroes" in the dependent variable, i.e. when no investment is attracted. 
Table 15. Ability to attract investors

\begin{tabular}{|c|c|c|c|c|}
\hline & No Competition (1) & No Competition (2) & Competition (3) & Competition (4) \\
\hline \multicolumn{5}{|c|}{ Count } \\
\hline Intercept & $2.519(0.531)^{* * *}$ & $1.800(0.192)^{* * *}$ & $0.682(1.243)$ & $1.075(0.221)^{* * *}$ \\
\hline Disclosure & $0.024(0.181)$ & $-0.064(0.088)$ & $-0.085(0.272)$ & $-0.273(0.077)^{* * *}$ \\
\hline Period & & $-0.006(0.006)$ & & $-0.011(0.010)$ \\
\hline OwnManFee & $-0.057(0.104)$ & $-0.093(0.028)^{* *}$ & $-0.251(0.171)$ & $-0.347(0.056)^{* * *}$ \\
\hline OwnPerfFee & $0.000(0.013)$ & $-0.006(0.003)^{\circ}$ & $-0.041(0.020)^{*}$ & $-0.022(0.005)^{* * *}$ \\
\hline OthManFee & $-0.532(0.178)^{* *}$ & $0.011(0.051)$ & $0.420(0.354)$ & $0.232(0.067)^{* * *}$ \\
\hline OthPerfFee & $-0.027(0.022)$ & $-0.001(0.006)$ & $0.027(0.046)$ & $0.024(0.007)^{* *}$ \\
\hline LagReturn & $0.053(0.012)^{* * *}$ & & $0.022(0.018)$ & \\
\hline \multicolumn{5}{|c|}{ Zero } \\
\hline Intercept & $-2.195(5.324)$ & $-3.070(1.002)^{* *}$ & $2.429(5.206)$ & $-0.193(0.989)$ \\
\hline Disclosure & $0.130(2.055)$ & $0.459(0.306)$ & $-0.529(1.267)$ & $-1.686(0.503)^{* * *}$ \\
\hline Period & & $-0.058(0.041)$ & & $-0.051(0.041)$ \\
\hline OwnManFee & $4.769(2.673)^{\circ}$ & $0.424(0.178)^{*}$ & $1.242(0.837)$ & $1.019(0.200)^{* * *}$ \\
\hline OwnPerfFee & $0.370(0.239)$ & $0.053(0.021)^{*}$ & $0.084(0.086)$ & $0.085(0.023)^{* * *}$ \\
\hline OthManFee & $-0.489(1.956)$ & $-0.434(0.262)^{\circ}$ & $-0.671(1.251)$ & $-1.368(0.361)^{* * *}$ \\
\hline OthPerfFee & $-0.927(0.563)^{\circ}$ & $0.020(0.031)$ & $-0.310(0.179)^{\circ}$ & $-0.057(0.037)$ \\
\hline LagReturn & $-0.784(0.455)^{\circ}$ & & $-0.048(0.061)$ & \\
\hline N. Obs & 48 & 624 & 48 & 624 \\
\hline
\end{tabular}

Note: Estimated outcomes of a Generalized Linear Mixed Model (Zero-Inflated Poisson) with random effects at the individual and session level are reported in columns (2) and (4) of the table. Estimated outcomes of a Zero-Inflated Poisson Model are reported in columns (1) and (3) of the table.

As shown by Table 15, the results of the Zero part are consistent with those of the Count part, overall. Specifically, when considering all trading periods (columns (2) and (4)) higher Management and Performance Fees increase the likelihood of not attracting investment. In contrast, higher Management Fees posted by other managers increase the likelihood of attracting investments, especially in Competition. When focusing on the first trading period and assessing the impact of past returns (columns (1) and (3)), the analysis shows that higher returns reduce the likelihood of not attracting investors in the No Competition condition, in line with what reported in the 
Count part.

As a robustness check, we re-estimated the regressions reported above adopting a Hurdle Poisson specification, to check for the impact of alternative modelling approaches to zeroes in the dependent variable. The robustness check largely corroborates evidence gathered from the zero-inflated specification. The few differences between the two specifications are limited to the zero component. Specifically, the hurdle model detects a positive and significant impact of others' Management Fees and a negative and marginally significant impact of Disclosure in No Competition. For what concerns the estimates focusing on the first trading period, in the hurdle model we observe a negative impact of Disclosure in Competition and no significant impact of others' performance fees in No Competition. 